\title{
LA COMPETENCIA EMOCIONAL E INTERPERSONAL EN EL ÁMBITO EDUCATIVO
}

Natalia Larraz Rábanos

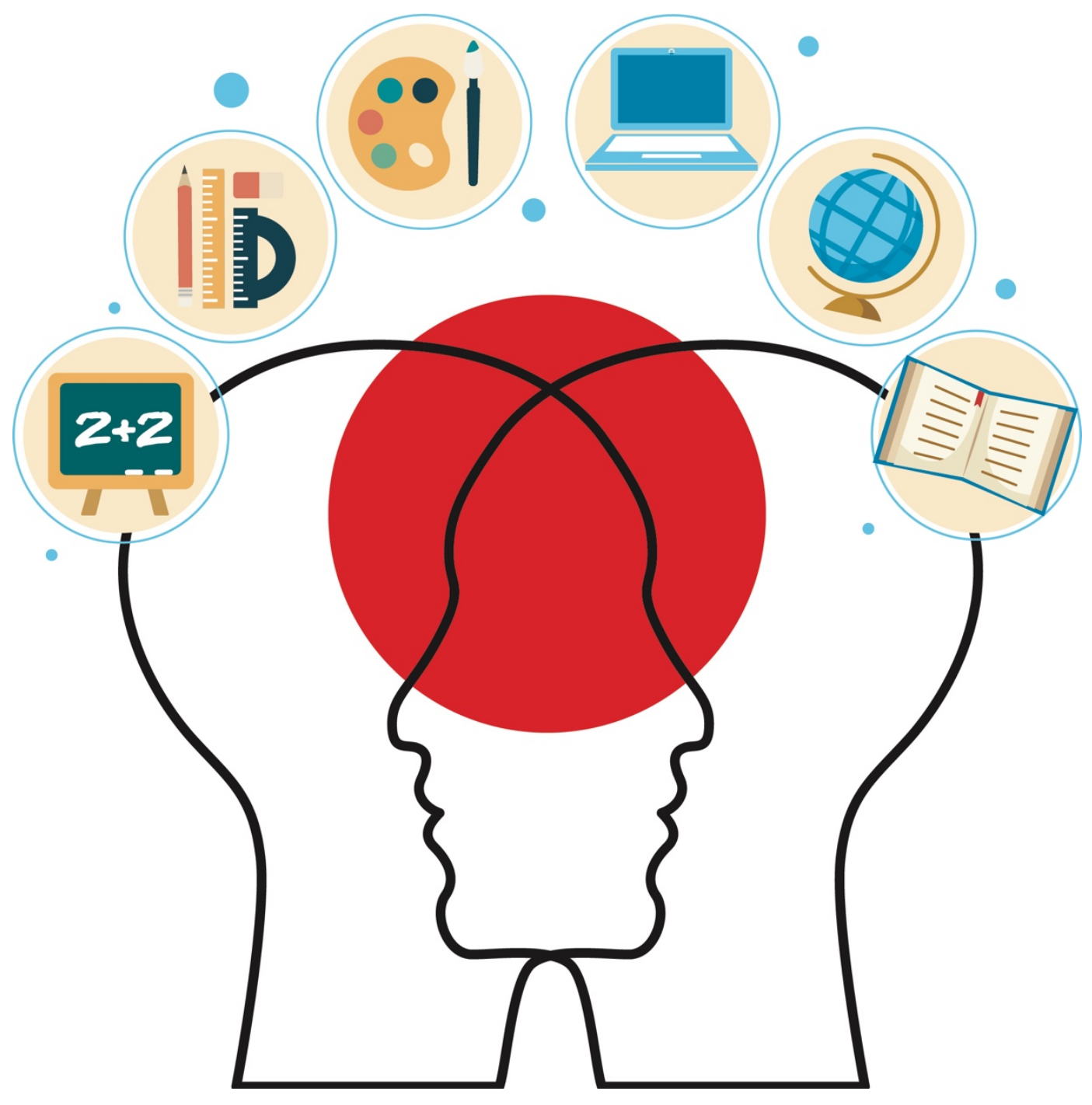




\title{
LA COMPETENCIA EMOCIONAL E INTERPERSONAL EN EL ÁMBITO EDUCATIVO
}

\author{
AUTORA: Natalia Larraz Rábanos
}

Todos los derechos reservados. Ni la totalidad ni parte de esta obra incluido el diseño de la cubierta puede reproducirse o transmitirse por ningún procedimiento electrónico o mecánico.

Cualquier forma de reproducción, distribución, comunicación pública o transformación de esta obra solo puede realizarse con la autorización de sus titulares, salvo excepción prevista por la ley.

Diseño de portada: Jacob Gragera Artal.

La portada ha sido diseñada usando imágenes de Freepik.com

Zaragoza, 2020.

ISBN: 978-84-09-22480-7 


\section{LA COMPETENCIA EMOCIONAL E INTERPERSONAL EN EL ÁMBITO EDUCATIVO}

\section{ÍNDICE:}

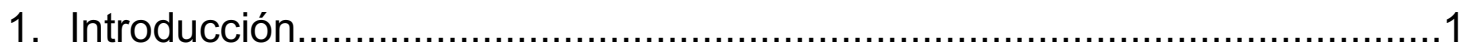

2. Competencia personal: conocimiento y regulación emocional......................5

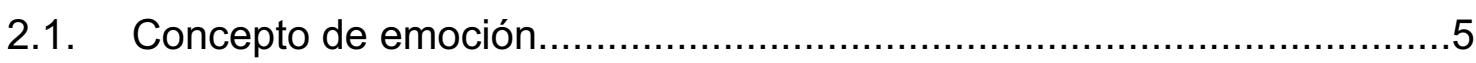

2.2. Conocimiento y regulación emocional..............................................19

3. Competencia social: desarrollo de las habilidades interpersonales.............32

3.1. La comunicación interpersonal y sus componentes.............................32

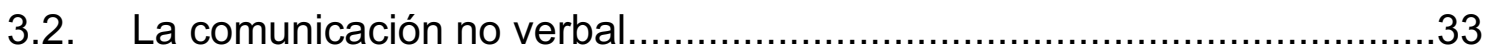

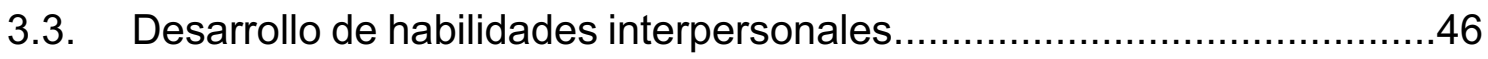

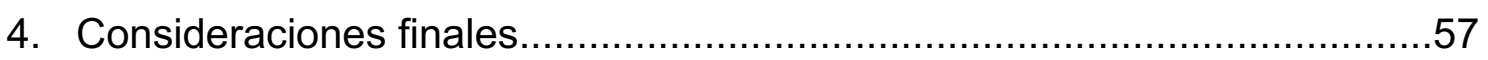

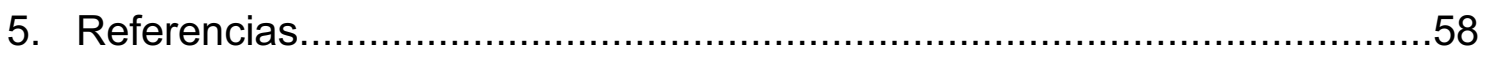

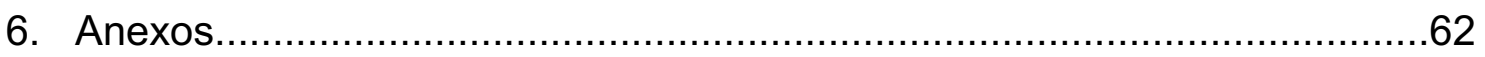




\section{LA COMPETENCIA EMOCIONAL E INTERPERSONAL EN EL ÁMBITO EDUCATIVO}

\section{INTRODUCCIÓN}

Desde la aparición del término Inteligencia Emocional se ha trabajado en su aplicación en la escuela, con el fin de fomentar la competencia emocional de los estudiantes a través de las medidas educativas propuestas a nivel de centro y de aula.

En nuestro caso partimos de los modelos teóricos actuales del intelecto humano que incluyen los aspectos sociales, prácticos e interpersonales y afectivos como un aspecto esencial a contemplar en la resolución de problemas adaptativos, desde que se concibe la inteligencia como un aspecto Múltiple, Modificable, Componencial y Experiencial (Larraz, 2015).

Este modelo está inspirado en distintas teorías sobre la inteligencia, como son la Teoría triárquica de Sternberg (1990), el modelo de las Inteligencias Múltiples de Gardner (1995) y el modelo de la Inteligencia Emocional de Salovey y Mayer (1990, 1997), término difundido posteriormente por Goleman (1996).

La teoría triárquica de la inteligencia propuesta por Sternberg (1990), que a su vez acuñó el término de Inteligencia exitosa para referirse a aquel tipo de inteligencia adaptativa al medio que permite resolver problemas de la vida real (Sternberg, 1997). La teoría triárquica de la inteligencia propone tres subcompoentes de la inteligencia; la componencial, la experiencial y la contextual que, a su vez, se componen en tres tipos de inteligencia; Inteligencia analítica, práctica y creativa, respectivamente. La inteligencia práctica sería aquella en la que se ve influida por las cuestiones sociales, interpersonales y relacionales. Se incluye dentro del componente contextual de la inteligencia que se ocupa de relacionar la inteligencia con el mundo exterior. Es un aglutinante de la adaptación al medio presente, la selección de un medio más óptimo y el modelado del medio con el fin de que se adecúe a las habilidades, intereses o valores de uno mismo. 
Por otro lado, el concepto de Inteligencia emocional, introducido inicialmente por Salovey y Mayer (1990) y posteriormente difundido por Goleman (1996) a nivel mundial, se ha definido como un conjunto de destrezas que contribuyen a lograr una adecuada percepción y expresión de las emociones, una adecuada regulación de las emociones y a la utilización de las emociones para motivarse, planificar y alcanzar los propios objetivos vitales. Otra definición válida de inteligencia emocional se describiría como el conocimiento de las emociones y de los sentimientos de uno mismo y su adecuada gestión y regulación en diversos contextos.

El concepto de emoción se ha definido como un estado complejo del organismo caracterizado por una activación del sistema nervioso que predispone a una respuesta generada a partir de un acontecimiento externo o interno.

A nuestro modo de entender, la educación emocional debe abarcar un conjunto amplio de actividades que implica el conocimiento de las propias emociones y la autorregulación de los propios estados afectivos para favorecer el logro de los compromisos personales y sociales. Esta propuesta recoge las aportaciones de Mayer y Salovey (1997) que postula que el fomento de la inteligencia emocional debe incluir el reconocimiento de las emociones y sentimientos en uno mismo y en los demás, el significado de los núcleos emocionales más distintivos, su dinámica y su regulación.

Para desarrollar la inteligencia emocional debemos aprender y desarrollar habilidades intrapersonales e interpersonales que nos ayuden a conocernos, a comunicarnos y a relacionarnos de forma eficaz con las personas que nos rodean.

Dichas habilidades parten de la teoría de las Inteligencias Múltiples propuesta por Gardner (1995) y están basadas en dos tipos de inteligencia que el mismo autor propuso, las cuales son:

- La inteligencia intrapersonal: constituye la habilidad que nos permite configurar una imagen de nosotros mismos y nos hace capaz de utilizar esa imagen para actuar en la vida de un modo más eficaz. 
- La inteligencia interpersonal: consiste en la capacidad de comprender a los demás y comprender sus motivaciones.

Goleman (1999) recogió en su propuesta la teoría de las Inteligencias múltiples, expresado en el marco de la competencia emocional y se basa en entender dos grandes factores, los cuales son: la competencia personal y la competencia social. La competencia personal, estaría ligada a la inteligencia intrapersonal e implicaría los siguientes aspectos:

- Conciencia de uno mismo: conciencia emocional, valoración adecuada de sí mismo, confianza en sí mismo.

- Autorregulación: autocontrol, confiabilidad, integridad, adaptabilidad, innovación.

- Motivación: Motivación de logro, compromiso, iniciativa.

Por otro lado, la competencia social, que estaría ligada a la inteligencia interpersonal, implicaría los aspectos relacionados con los siguientes aspectos:

- Empatía

- Habilidades sociales.

Según lo comentado, el desarrollo de la inteligencia emocional en la escuela, partiendo del conocimiento y reconocimiento de nuestras propias emociones básicas, y posterior conocimiento y reconocimiento de dichas emociones en las personas que nos rodean, va a ser fundamental para lograr un aprendizaje más amplio y eficaz y a desenvolvernos mejor y lograr un desarrollo integral como personas.

Además de ello, podemos hablar de un componente social e interpersonal, que se establece en la relación con el estudiante, que hemos denominado, vínculo educativo. El vínculo educativo entre sujeto y agente educativo, entre el alumnado y el profesor. Dicho vínculo, en su asimetría, se da una transferencia de afectos y una estructura relacional repetida en la figura del docente y atribución de saber (en detrimento), etc., establecida a través del lenguaje, en la que median los contenidos y un objetivo, que es la apropiación de saberes y la 
incorporación del alumnado al mundo de la cultura (ver figura 1 en la que se muestra el Triángulo «herbartiano» acuñado por Núñez (2008, en Tizio, 2008).

Dicho triángulo se compone de tres aspectos:

- El AGENTE EDUCATIVO: Lo que opera en el aprendizaje y en la transmisión del saber es el deseo de educar, hallando un equilibrio entre lo general y lo particular para causar el consentimiento del sujeto. Es necesario, también, proporcionar un lugar al alumnado y tener un interés por él (Tizio, citada por Mendel, 2008, p. 51)

- EL SUJETO EDUCATIVO: Consiente a la oferta educativa propuesta, con un esfuerzo, facilitado por el establecimiento de un vínculo con su educador, en quien, si todo va bien, podrá confiar y ser reconocido como sujeto. Irá de una alienación a los saberes que le proponen, a una progresiva separación, haciendo de esos nuevos conocimientos su propia construcción

- LOS BIENES CULTURALES O CONTENIDOS, dependen de la cultura y el lugar, es importante considerar y trabajar una oferta educativa que permita un consentimiento y demanda del alumnado. En todo caso ¿Qué hay que aprender?

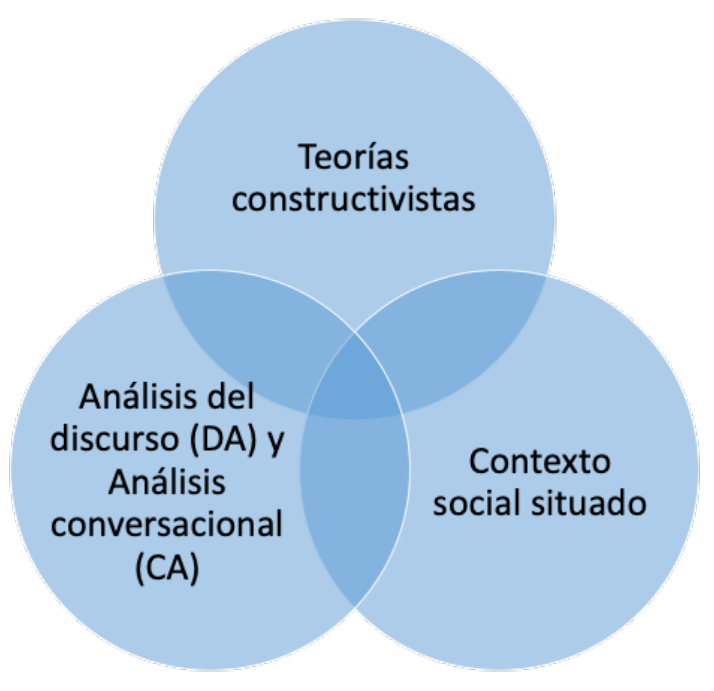

Figura 1. El vínculo educativo, el Triángulo Herbatiano. 


\section{COMPETENCIA PERSONAL: CONCIMIENTO Y REGULACIÓN EMOCIONAL}

\subsection{CONCEPTO DE EMOCIÓN}

La palabra emoción proviene del latín movere (mover), con el prefijo e, que puede significar hacia fuera. Sacar fuera de nosotros mismos (ex-movere). Dicha afirmación indica que la tendencia a actuar está presente en cada emoción. Motivación tiene la misma raíz latina.

Emoción se define como un estado complejo del organismo caracterizado por una excitación o perturbación que predispone a una respuesta organizada generada a partir de un acontecimiento externo o interno.

Otra definición que a nuestro entender acoge con bastante precisión la complejidad del término es propuesta por Acosta (2008):

Una compleja combinación de procesos corporales, perceptivos y aptitudinales que producen en las personas un estado psicológico global, que puede ser positivo o negativo, de poca o mucha intensidad y de corta o larga duración, o mezclas de esos elementos, y que genera una expresión gestual que puede ser identificada por las demás personas (p.48).

La emoción tiene tres componentes (Bisquerra, 2000):

- Componente neurofisiológico: respuestas involuntarias del organismo; taquicardia, sudoración, rubor, sequedad en la boca, presión sanguínea, secreciones hormonales, etc.

- Cognitivo: vivencia subjetiva que coincide con lo que se denomina sentimiento. Permite etiquetar a una emoción, en función del dominio del lenguaje. Se puede conocer a través del autoinforme.

- Comportamental: expresiones faciales (23 músculos), tono de voz, volumen, ritmo, movimientos del cuerpo, etc. Este componente se puede controlar. 
Las emociones afectan al estado de salud de una persona pudiendo favorecer y mejorar el estado de la calidad de vida de una persona o empeorarlo.

- Las emociones negativas pueden afectar de manera nociva a la salud y actuar como desencadenantes o coadyuvantes en el desarrollo de enfermedades, recaídas o agravamiento de las mismas.

- Las emociones positivas tienen efectos curativos de tal modo que hasta pueden cambiar el curso de una enfermedad.

\subsubsection{Emociones, sentimientos y afectividad.}

Cabría distinguir entre dos nociones básicas relacionadas con las emociones, que son las nociones de emoción y sentimiento. Según Torrabadella (1998), las emociones son activaciones físicas breves que se desencadenan en nosotros como respuesta de algo y los sentimientos son definidos como un estado psíquico complejo por parte de las emociones, y se diferencian de las emociones en que son conscientes y tienen una duración superior a la emoción. De este modo, según esta autora, los sentimientos nos permiten tener conciencia de nuestro estado de ánimo. Para ella, la fórmula que constituye un sentimiento es la siguiente: EMOCIONES + PENSAMIENTO = SENTIMIENTO EMOCIONAL.

Por ejemplo, ante una respuesta física emocional de activación puedes pensar muchas cosas. Entras en una sala donde hay un grupo y todos se ríen:

- "He hecho el ridículo" = sentirás miedo

- "Se están divirtiendo, vamos a pasarlo bien" = sentirás alegría.

- "Son maleducados" = sentirás enfado

- "Creo que les gusto porque al entrar se han alegrado" = Sentirás aprecio.

Por lo tanto, las emociones son los aspectos básicos que componen los sentimientos, que son los aspectos afectivos que a su vez conforman un estado de ánimo. Los sentimientos engloban las emociones, pero añaden duración, asociándolas a un pensamiento e imponiéndoles un significado psicológico.

La aportación realizada por López Sánchez (2009), define tres dimensiones emocionales diferentes, que son: el humor, las emociones y los sentimientos, 
entendidos éstos últimos como una interpretación mental de nuestras emociones. Además, establece una diferencia clara entre las emociones y los sentimientos de lo que son los afectos sexuales y sociales. Para este autor, los afectos sexuales serían el deseo, la atracción y el enamoramiento y los afectos sociales se relacionarían con el apego (a los cuidadores familiares o a la pareja sexual), con la amistad con algunas personas y con el sistema de cuidados (a los hijos, a la pareja o a otras personas).

Es decir, así como las emociones y los sentimientos suponen una respuesta ante una situación dada y responden a la competencia personal, los afectos sexuales y sociales están unidos a la competencia social y a la inteligencia interpersonal y a los vínculos afectivos que se establecen con los demás como una necesidad básica del ser humano. En este sentido, las emociones juegan un papel fundamental en las relaciones humanas en la forma de establecer las relaciones vinculares con los demás y con nuestros progenitores, amigos, cuidadores, etc. Dichas relaciones estarían asociadas a la necesidad de afecto.

Es por ello que las emociones tienen una función motivadora, adaptativa, informativa y social y además pueden jugar una función importante en el desarrollo personal del individuo (Bisquerra, 2000; 2002; 2009). De este mismo modo, podemos indicar que nuestro bienestar subjetivo, va a depender en buena medida de cómo "sentimos la vida", lo bien o lo mal que "nos sentimos viviendo", que depende a su vez del mundo afectivo y social que nos rodea (López Sánchez, 2009). El modelo pentagonal del desarrollo de competencias emocionales para desarrollar en el ámbito educativo que proponen Bisquerra y García (2018), se compondría de los siguientes elementos para su desarrollo:

- Conciencia emocional: tomar conciencia y dar nombre a las propias emociones, comprensión emociones de los demás, tomar conciencia de la interacción entre emoción, cognición y comportamiento.

- Regulación emocional: autogenerar emociones positivas, habilidades de afrontamiento, regulación de emociones y sentimientos, expresión emocional apropiada. 
- Autonomía emocional: resiliencia, análisis crítico de normas sociales, actitud positiva, autoeficacia emocional, responsabilidad, automotivación y autoestima.

- Competencia social: gestionar situaciones emocionales, prevención y solución de conflictos, asertividad, comportamiento prosocial y cooperación, practicar comunicación receptiva, respeto por los demás, dominar las habilidades sociales básicas.

- Competencias para la vida y el bienestar: fijar objetivos adaptativos, tomar decisiones, fluir, bienestar emocional, buscar ayuda y recursos, ciudadanía activa y participativa, crítica y responsable.

En este documento, hablaremos de una manera u otra de este tipo de competencias.

\subsubsection{Clasificación de las emociones y tipos de emoción.}

Hoy en día parece haber consenso en la existencia de cinco o seis emociones básicas, aunque puede haber divergencia entre los distintos autores en relación a cuáles son dichas emociones básicas. En este caso, vamos a hacer referencia a las seis emociones básicas propuestas por Damásio (2005) que son las siguientes: miedo, ira, asco, sorpresa, tristeza y alegría, que están basadas en el principio de placer/displacer o placer/dolor que tienen como base las pulsiones y los instintos.

Podemos distinguir además entre emociones positivas y negativas. Bisquerra (2000) se basa en las siguientes dimensiones para clasificar las emociones: placer- displacer, arousal (activación), profundidad o absorción intensa, intensidad (fuerza con la que se experimenta una emoción), especificidad (posibilita calificar la emoción) y temporalidad (duración de las emociones).

A pesar de las distintas dimensiones que se pueden destacar de las emociones, el aspecto más destacado para realizar una clasificación de las mismas es el de considerar la bipolaridad de las emociones en dos ejes placer-displacer. También desatacar que ninguna de las emociones por sí mismas tienen un 
carácter negativo o positivo, ya que todas ellas son adaptativas y sirven para comprender mejor nuestro mundo interior.

Por último, cabría añadir un tercer tipo de emoción que sería las emociones neutras o ambiguas, quedando dicha clasificación explicada del siguiente modo:

- Las emociones negativas son desagradables, se experimentan cuando se bloquea una meta, ante una amenaza o una pérdida. Estas emociones requieren de energía o movilización para afrontar la situación de manera más o menos urgente.

- Las emociones positivas, son agradables. Se experimentan cuando se logra una meta. El afrontamiento se basa en el disfrute y el bienestar que proporciona esa emoción.

- Las emociones ambiguas no son ni positivas ni negativas, o pueden ser ambas según las circunstancias. Se parecen a las positivas en cuanto a la brevedad temporal pero también a las negativas por la movilización de recursos.

Para Lazarus (1991), las emociones negativas son el resultado de una evaluación desfavorable (incongruente) respecto a los objetivos propios y las positivas de una evaluación favorable (congruente) respecto al logro de objetivos o de acercarse a ellos.

En el documento de Universo de Emociones, que desarrolla Bisquerra, junto a Punset y Gea (2016), se explican de un modo más detallado, creando un universo de constelaciones a partir de las cuales gravitan las emociones en torno a estas tres dimensiones, dicho universo se puede ilustrar mediante la figura 2. 


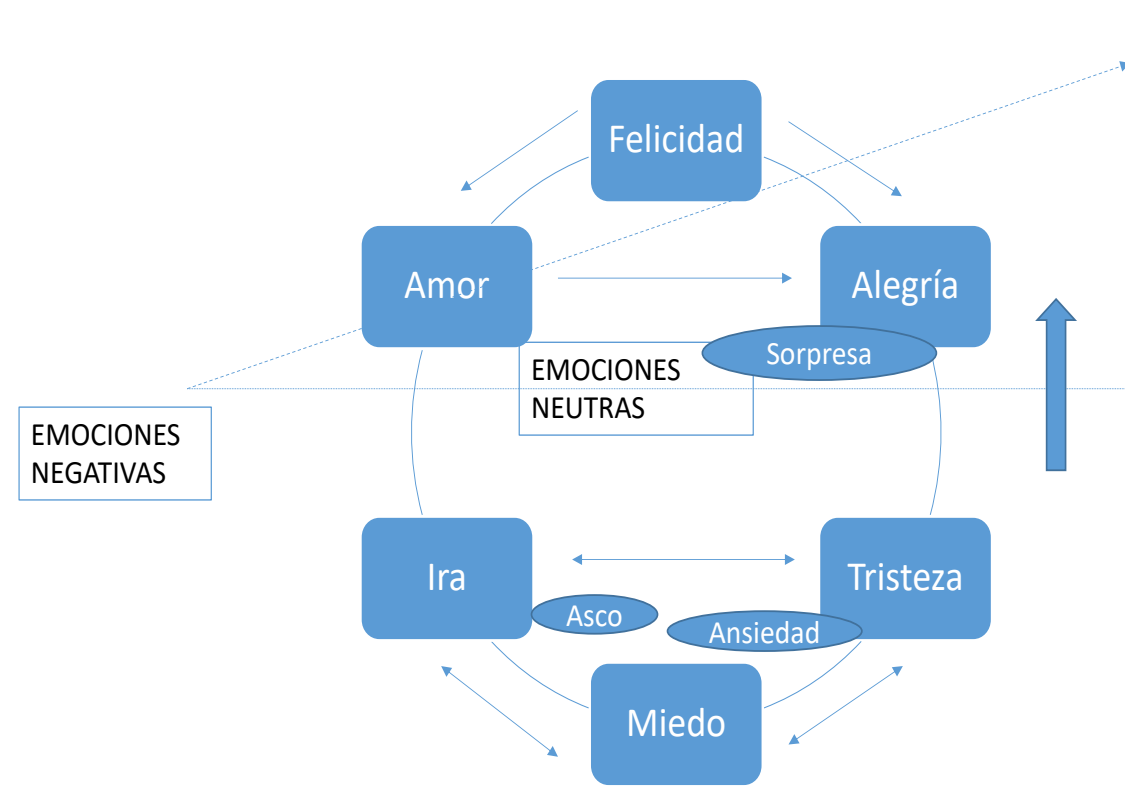

Figura 2. Universo de emociones.

Hemos adoptado el modelo de Bisquerra (2000) para describir una serie de emociones negativas, positivas y neutras del modo que proponemos a continuación.

1. Emociones negativas:

- La ira: se genera cuando tenemos la sensación de haber sido perjudicados. Es una reacción de irritación, furia o cólera desencadenada por la indignación o el enojo de sentir vulnerados nuestros derechos.

La ira puede estar ocasionada por la frustración que supone algún obstáculo para lograr alcanzar nuestros objetivos o por la sensación de ser manipulado, engañado, traicionado o herido.

El daño puede ser físico o moral, generalmente está causado por amenazas simbólicas a nuestra autoestima o dignidad personal, normalmente atribuido a la mala intención por parte de otra persona y que no está en consonancia con las normas sociales establecidas. 
El miedo y la ira son las respuestas más impulsivas que requieren de respuestas más urgentes. La ira es la emoción potencialmente más peligrosa ya que su propósito es funcional, es destruir y puede conllevar respuestas agresivas verbales y físicas.

Existe "ira hacia dentro" e "ira hacia fuera". La primera es la supresión de la emoción hacia alguien que se convierte en irritación consigo mismo. La segunda se refiere a la expresión de la ira hacia otras personas distintas a las que la han provocado.

La ira aumenta conforme más pensamos en las causas que la han generado, y una forma de afrontarla es a través de los pensamientos, ver las cosas de forma diferente. Otra solución es intentar olvidarlo y dedicarse a otras actividades personalmente más satisfactorias.

- El miedo: el miedo es la emoción que se experimenta ante un peligro real e inminente. Es activado por amenazas a nuestro bienestar físico o psíquico.

Según Alban (2007) "El origen del miedo lo encontramos en la falta de confianza y seguridad personal, en la insuficiente preparación académica o en la natural reacción que experimenta toda persona al internarse en una situación inhabitual" (p. 42).

Normalmente el miedo se produce por algún acontecimiento físico, en estos casos son miedos reales y justificados. Pero en otras ocasiones, se tienen miedos a supuestos peligros imaginarios, en estos casos son considerados como fobias.

La forma de afrontar el miedo más habitual es la huida o la evitación de la situación en la que se ha provocado la emoción, cuyo objetivo es proteger a la persona.

La activación del sistema nervioso autónomo es importante durante las situaciones de emergencia, que es cuando mayoritariamente actúa el miedo. 
Por ejemplo: se percibe el brillo de algo; y esto puede ser interpretado como el brillo de un cuchillo o el brillo de un espejo. La persona interpreta la situación y la respuesta ante dicha interpretación puede provocarle miedo u otra emoción.

En cuanto se interpreta un problema como amenaza, se activa una respuesta en la que aumenta el arousal y la tensión y provoca una respuesta de emergencia del organismo. Se producen cambios fisiológicos que son resultado de la activación de una de las dos partes del Sistema Nervioso Autónomo, a saber:

- El sistema simpático actúa para preparar al cuerpo durante situaciones de tensión y de emergencia, coordinando todos los recursos del organismo para responder ante los peligros (respuesta de huída o de pelea).

- El sistema parasimpático actúa para calmar al cuerpo después de que se resolvió la situación de emergencia y también pone medios para que el cuerpo mantenga reservas de fuentes de energía, como nutrientes y oxígeno.

- El sistema simpático y el parasimpático actúan bajo el principio de activación recíproca.

La evaluación como mediador cognitivo de la respuesta de activación interpreta la situación en cuatro sentidos:

- Amenaza: anticipación de un daño

- Daño o pérdida: daño psicológico que se ha producido

- Desafío; valoración de una situación percibida como ganancia y amenazante.

- Beneficio: no induce estrés.

Las manifestaciones fisiológicas del miedo suelen ser:

- Aumento del ritmo cardiaco

- Enrojecimiento facial

- Respiración alterada 
- Temblor en las manos

- Sequedad en la boca

- Sudoración en las palmas de las manos

- Presión del estómago

Las características físicas y psíquicas del miedo suelen ser (Güel y Muñoz, 2000):

- Cejas levantadas y fruncidas al mismo tiempo

- Arrugas en el centro de la frente

- Párpado superior levantado y párpado inferior en tensión

- Boca abierta y los labios o bien tensos y estirados hacia atrás o bien estrechos y tirados también hacia atrás.

El origen del miedo puede ser por varios motivos, estos son los siguientes: a) Miedo a que nuestro propio interior, nuestra intimidad, quede al descubierto; b) Sensación de incapacidad para responder de forma eficaz al requerimiento de la tarea; c) Miedo a cometer algún error; d) Clima adverso; e) Pensamientos y actitudes negativas; f) Temor a que queden al descubierto nuestras limitaciones, carencias o defectos; g) Miedo a perder el control.

Cuando el miedo se prolonga pueden aparecer estados de ansiedad, que se puede definir como una reacción emocional compleja ya que el principal mediador que actúa para que se genere son los pensamientos, que muchas veces pueden ser inconscientes.

La ansiedad, se puede identificar como un estado emocional complejo que resulta de una respuesta cognitiva anticipatoria resultante de la interpretación de una situación potencialmente amenazante o nociva. La preocupación es la base de la ansiedad, la ansiedad es la anticipación de un peligro futuro, cuyos desencadenantes son imprevisibles e imprecisos.

La tarea de la ansiedad es procurar soluciones a los peligros de la vida, anticipando los efectos negativos antes de que éstos lleguen. El problema puede aparecer cuando esta preocupación se convierte en crónica 
(porque la preocupación persiste ante la existencia o no de peligros, que son percibidos como igualmente amenazantes), sin llegar a una solución real y efectiva del problema, generándose de esta forma un estado general de ansiedad como rasgo de la personalidad. La respuesta de ansiedad en estos casos es ser más intensa y persistente, representa un malestar clínico significativo.

Para prevenir la ansiedad se proponen varias opciones: a) Identificar las situaciones que generan preocupación previamente a que se genere la espiral de ansiedad; b) Utilizar técnicas de relajación; c) Utilizar técnicas de reestructuración cognitiva. Cambiar pensamientos irracionales por pensamientos más realistas.

- Tristeza: suele provocarse por la pérdida de algo que se valora como importante. Es más, un estado de ánimo que una emoción aguda. La tristeza supone una respuesta de un suceso pasado, donde nadie es culpable. La tristeza se asocia al Ilanto.

La tristeza puede producir una pérdida o incapacidad de experimentar placer, dicha incapacidad se denomina anhedonia, síntoma asociado a la depresión.

Las características físicas y psíquicas de la tristeza se pueden resumir del siguiente modo (Güel y Muñoz, 2000):

- Ángulos interiores de los ojos hacia arriba

- Frente arrugada y triángulos de la piel de las cejas.

- Comisuras de los labios hacia abajo y labios temblorosos.

- Tensión muscular general baja. Decaimiento global del cuerpo. Posible palidez. Ritmo respiratorio y cardiaco lentos.

- Estados afectivos asociados: Apatía, desinterés, desmotivación, desánimo general, falta de deseo.

- Vergüenza: sentimiento de pérdida de dignidad por alguna falta cometida por uno mismo o por una humillación o un insulto. El afrontamiento de la vergüenza debe pasar por superar sentimientos de culpabilidad, de 
inferioridad y timidez. Para lograrlo se deben cambiar los pensamientos generados por la persona.

Características físicas de la vergüenza:

- Bajar la mirada.

- Dejar caer la cabeza

- Volver la cara para evitar mirar directamente.

- Cruzarse de brazos y piernas

- Sonrojarse.

2. Emociones positivas:

- Alegría: emoción que se produce tras un suceso favorable. Las principales causas de la alegría son generalmente las relaciones con los amigos, las satisfacciones básicas y las experiencias exitosas. La alegría es una de las emociones básicas que constituye la felicidad.

Las características físicas de la alegría serían (Güel y Muñoz, 2000):

- Comisura de los labios hacia atrás y arriba.

- Boca abierta, sonriente, enseñando o no los dientes.

- Ojos abiertos, brillantes.

- Mejillas levantadas.

- Humor: más que una emoción es un estado afectivo. El humor es tener buena disposición para hacer alguna cosa. Los desencadenantes del humor suelen ser estímulos que se consideran divertidos o graciosos, y que pueden provocar respuestas abiertas como la sonrisa, la risa o la carcajada. Según Bisquerra (2000) el humor y la risa contrarrestan las experiencias de las emociones negativas: intensifican la confianza entre las personas y preparan al organismo para experimentar placer sensorial, amortiguan el estrés, reducen el malestar y el dolor y bajan la tensión. El humor y la risa son altamente beneficiosos para la salud mental y física.

- Felicidad: La felicidad es un estado de bienestar, por lo tanto, es un estado deseable y deseado. Es la forma de valorar la vida en su conjunto, es la 
percepción y valoración global de las experiencias vitales, hay algunos factores que figuran como preponderantes, que son la familia y el trabajo, otros como las relaciones sociales, el tiempo libre, la ausencia de enfermedades, los ingresos económicos y la congruencia entre lo que se desea y lo que se posee, son también muy importantes.

La felicidad no es fugaz, sino que es un estado que se mantiene con cierta estabilidad temporal. La felicidad facilita la empatía y la aparición de conductas altruistas, que genera actitudes positivas hacia los demás y hacia uno mismo.

Compartimos la opinión de Bisquerra (2000) al decir que la psicoterapia emocional se ha centrado tradicionalmente en las emociones negativas y que ha habido un olvido desde la psicología y la educación de las emociones positivas. La educación emocional se debe enfocar hacia la prevención de los efectos negativos de las perturbaciones emocionales y al desarrollo de las emociones positivas. En este sentido, este autor propone que:

Dentro del área de prevención y desarrollo está en fase emergente la educación emocional, que se considera como una prevención inespecífica enfocada al desarrollo de competencias emocionales: conocimiento de las propias emociones y de las emociones de los demás, regulación de las emociones, control del impulso, tolerancia a la frustración, autoestima, automotivación, relaciones interpersonales positivas, etc.; todo ello enfocado al bienestar personal y social (p. 1).

3. Emociones ambiguas:

- Sorpresa: la sorpresa es una reacción provocada por algo imprevisto o extraño.

- Esperanza: temer lo peor, pero ansiar mejorar.

- Compasión: preocupación altruista por el sufrimiento ajeno y deseo de ayudarles y aliviarles. La compasión ha sido relacionada con la empatía. 
En este punto, recomendamos realizar el ejercicio 1.1 de los anexos de Autoconocimiento emocional.

En la tabla 1 se muestra un cuadro resumen con los tipos de emoción existente, el desencadenante que puede ocasionarlo y el tipo de respuesta que provoca. En la tabla 2 se presentan los temas centrales de las emociones mencionadas con anterioridad y se incluye alguna otra emoción relevante.

Tabla 1. Tipos de emoción, desencadenante y respuesta provocada.

\begin{tabular}{lll}
\hline EMOCIÓN & DESENCADENANTE & RESPUESTA \\
\hline Ira & $\begin{array}{l}\text { Prejuicio, ofensa, desprecio } \\
\text { frustración }\end{array}$ & Agresiva: ataque o violencia \\
& & $\begin{array}{l}\text { No agresiva. Implicarse o hablar para } \\
\text { resolver la situación }\end{array}$ \\
\hline Miedo & Peligro, inseguridad o amenaza & Ataque, fuga, inmovilidad, estrés \\
\hline Tristeza & Pérdida o cambios & Alcoholismo/drogas \\
& & Desmotivación general \\
& & Depresión/suicidio \\
\hline Alegría & Bienestar o placer & Estado de humor positivo \\
& & Realización de objetivos \\
\hline Vergüenza & Sentimiento de pérdida de dignidad & Sentimiento de culpabilidad, timidez. \\
& por dos motivos: & \\
& $-\quad$ Falta cometida por uno mismo & \\
& $-\quad$ Humillación o insulto & \\
\hline
\end{tabular}


Tabla 2. Temas centrales de algunas emociones adaptado de Bisquerra (2000, p. 97).

\section{TEMAS CENTRALES DE ALGUNAS EMOCIONES}

- IRA: Una ofensa contra mí o lo mío que me disminuye.

- MIEDO: Un peligro físico real e inminente, concreto y arrollador

- ANSIEDAD: Enfrentarse a una amenaza incierta, existencial.

- TRISTEZA: Experimentar una pérdida irreparable

- VERGÜENZA: Fracasar en vivir de acuerdo con el yo ideal

- CULPA: Transgredir un imperativo moral

- REPUGNANCIA: Estar demasiado cerca de algo (objeto, idea) "indigesto".

- CELOS: Resentimiento frente a una tercera persona parte por la pérdida o amenaza del afecto de otra persona.

- ENVIDIA: Querer lo que el otro tiene.

- AMOR: Desear o participar en afecto, habitualmente pero no necesariamente recíproco.

- FELICIDAD: Hacer progresos razonables hacia el logro de un objetivo.

- ORGULLO: Mejorar la identidad personal mediante el rendimiento, un honor, un mérito o algo deseado, logrado por sí mismo o por alguien del grupo con el cual uno se identifica.

- ALIVIO: Una condición dolorosa incongruente con los objetivos personales que cambia a mejor o que cesa.

- ESPERANZA: Temer lo peor, pero ansiar lo mejor.

- COMPASIÓN: Sentirse afectado por el sufrimiento de otro y desear su ayuda. 


\subsection{CONOCIMIENTO Y REGULACIÓN EMOCIONAL.}

La confianza en uno mismo radica en tener coraje derivado de la certeza de nuestras capacidades, valores y objetivos. La confianza y seguridad personal de uno mismo es un estado psicológico; producto de su competencia, conocimientos y habilidades, ello le permite enfrentar situaciones adversas y salir airoso de ellas (Alban, 2007).

Debemos fomentar la confianza y la seguridad personal logrando una mayor competencia personal en el manejo de las emociones, un mejor control y regulación de las mismas para enfrentarse a la audiencia de forma eficiente. Para lograr una confianza y seguridad personal mayor se pueden tener en cuenta los siguientes componentes:

1. El conocimiento de las emociones: la expresión de las emociones y el reconocimiento de las emociones.

2. El desarrollo de la autoestima.

3. Control y regulación emocional.

El objetivo último del autoconocimiento emocional sería aprender a reconocer y manejar las emociones, para saber cómo te sientes y tener la libertad de actuar en consecuencia.

\subsubsection{Conocimiento de las emociones.}

El conocimiento de las propias emociones pasa por comprender su forma de expresión, así como los desencadenantes que las provocan para después poder reconocerlas en nosotros mismos. Para lograr el conocimiento de las propias emociones sería preciso dar estos pasos:

1. Descubrir, sentir y percibir las propias emociones. Qué sientes del exterior: sensaciones.

2. Atender lo que se percibe en tu interior. Qué sientes en tu interior: emociones.

3. Atender lo que piensas. Qué piensas conscientemente acerca de las emociones: sentimientos y pensamientos. 


\subsubsection{La expresión de las emociones.}

Las expresiones faciales de de las emociones son universales e innatas. Torrabadella (1998) indica que generalmente la expresión de la emoción es involuntaria y constante. Según esta autora, las caras van cambiando y dando mensajes que son contestados en presencia de los demás. Se puede aprender a ver en los rostros de las personas muchas expresiones que para ellas son inconscientes. Expresamos en centésimas de segundo muchas emociones sin ser conscientes de ello. Para esta autora, las seis emociones básicas que se transmiten a través de las expresiones faciales son: alegría, sorpresa, tristeza, miedo, ira y asco/desprecio.

Cada emoción se concreta en una forma de expresión a través del as regiones faciales siguientes:

- La frente/cejas

- Los ojos/párpados

- La parte inferior de la cara.

La información que se muestra en las tablas 4 y 5 es un resumen de los signos de las expresiones faciales que se pueden utilizar para interpretar conformidad o disconformidad de que son testigo, dicha información ha sido tomada de Anguera (1989).

Tabla 4. Información proporcionada por la parte frontal de las cejas.

\begin{tabular}{ll}
\hline POSICIÓN DE LAS CEJAS & INTERPRETACIÓN \\
\hline Completamente elevadas & Incredulidad \\
\hline Medio elevadas & Sorpresa \\
\hline Normales & Neutralidad \\
\hline Algo fruncidas & Confusión, desacuerdo \\
\hline Fruncidas & Enfado
\end{tabular}


Tabla 5. Signos de las expresiones faciales (adaptado de Anguera, 1989).

\begin{tabular}{|c|c|c|}
\hline $\begin{array}{l}\text { PARTE DE LA } \\
\text { CARA }\end{array}$ & CONFORMIDAD & DISCONFORMIDAD \\
\hline FRENTE & $\begin{array}{ll}\text { - } & \text { Lisa } \\
\text { - } & \text { Pequeñas arrugas } \\
& \text { horizontales extendidas }\end{array}$ & $\begin{array}{ll}\text { - } & \text { Arrugas horizontales en medio de la } \\
\text { frente } \\
\text { - } & \text { Depresión horizontal, arrugas } \\
& \text { profundas o depresión vertical }\end{array}$ \\
\hline CEJAS & $\begin{array}{l}\text { - Horizontales, ausencia de } \\
\text { arrugas } \\
\text { - } \quad \text { Una ceja arqueada } \\
\text { - } \quad \text { Ligero replegamiento de } \\
\text { una o ambas cejas } \\
\text { - } \quad \text { Ambas cejas arqueadas }\end{array}$ & $\begin{array}{ll}\text { - } & \text { Depresión sobre una o ambas cejas } \\
\text { - } & \text { Fruncimiento } \\
\text { - } & \text { Aproximación central con forma de } \mathrm{V} \\
\text { - } & \text { Forma de } \mathrm{V} \text { y depresión sobre una o } \\
& \text { ambas }\end{array}$ \\
\hline PÁRPADOS & $\begin{array}{l}\text { - Inmóviles y ausencia de } \\
\text { pliegues }\end{array}$ & $\begin{array}{ll}\text { - } & \text { Alteración en los párpados } \\
& \text { superiores o pliegues } \\
\text { - } & \text { Ojos cerrados con pliegues } \\
& \text { exagerados } \\
\text { - } & \text { Abrir y cerrar los ojos con rapidez }\end{array}$ \\
\hline BOCA & $\begin{array}{ll}\text { - } & \text { Risa (boca abierta o } \\
& \text { cerrada) } \\
\text { - } & \\
\text { - Sonrisa } & \\
\text { Boca cerrada sin } & \\
& \text { movimiento }\end{array}$ & $\begin{array}{ll}\text { - } & \text { Rictus hacia la izquierda o derecha } \\
\text { - } & \text { Boca fruncida y labios apretados } \\
\text { - } & \text { Labio inferior o dientes sobre labio } \\
& \text { superior o viceversa }\end{array}$ \\
\hline NARIZ & $\begin{array}{l}\text { - Inmóvil, sin arrugas ni } \\
\text { alteración }\end{array}$ & $\begin{array}{l}\text { - } \quad \text { Movimiento aletas de la nariz } \\
\text { - } \quad \text { Arrugas en la nariz }\end{array}$ \\
\hline
\end{tabular}

La expresión de la cara debe ser coherente con las palabras que se transmiten. Todas las expresiones y todos los estados de ánimo tienen en el rostro humano su expresión característica, lo que nos permite leer sus sentimientos a través de sus gestos y expresiones faciales. Es cierto que podemos intentar fingir ciertas emociones para disimularlas y esconderlas, pero normalmente cuando esto ocurre, las personas no saben expresarlas con naturalidad como, por ejemplo: cómo hacerlas surgir súbitamente, cuánto rato mantenerlas y con qué rapidez hacerlas desaparecer. 
La expresión de emociones es algo universal y su represión es algo cultural. Por ejemplo, en niños ciegos de nacimiento, ya se observan expresiones de sonrisa de sociabilidad a las cinco semanas. Los niños ciegos de nacimiento ríen, lloran, y hacen pucheros, ponen caras de enfado, miedo o tristeza sin haberlo observado en otras personas. Cada cultura tiene sus propias formas de expresión emocional, ya que hay culturas más "frías" que otras donde la expresión emocional se oculta más que en otras. A pesar de todo, la expresión suele aflorar siempre que no se está en sociedad.

\subsubsection{El reconocimiento de las emociones.}

Vivimos del afecto de los demás y las fuentes de afecto que tenemos nos enseñan a recibir formas de afecto que en muchas ocasiones son negativas (en vez de darnos amor, se nos riñe y desprecia constantemente) y preferimos sus desprecios y castigos antes que sentirnos ignorados (Torrabadella, 1998). Pero lo realmente importante es reconocer el sentimiento que nos causan las personas que nos rodean, si este es dañino o es afectivo. Sólo si somos conscientes de nuestras propias emociones podremos desarrollar la empatía (reconocer esas emociones en los demás y mostrar un estado afectivo congruente con el suyo).

La inteligencia emocional se puede desarrollar siendo consciente de cuáles son las emociones que reprimes de forma involuntaria, este primer paso será el necesario para comprender estas emociones en los demás.

Los pasos a seguir para desarrollar la inteligencia emocional serían los siguientes:

- Darnos cuenta de nuestras propias emociones

- Pensar de forma adecuada acerca de las mismas

- Comprender las emociones en los demás

En palabras de Torrabadella (1998) "Nadie puede pensar acerca de una emoción que no reconoce y nadie puede comprender las emociones de los demás si no asume antes las suyas propias" (p. 46). Para ella, las emociones afectan a nuestros pensamientos siempre que éstas no son conscientes. El inconsciente 
es la fuente de nuestros pensamientos por lo que determina nuestra vida. Podemos trabajar nuestro inconsciente observando qué pensamientos nos genera. Esto hará posible saber qué emoción está reprimida en el inconsciente. Una vez que se ha detectado la emoción, se puede evocar voluntariamente para ser conscientes de la enorme tensión que supone reprimirla. Si, por ejemplo:

en tu inconsciente habita el miedo, recordarás a las personas que te evocan miedo, pensarás en ellas, serán importantes para ti, y con tu expresión atraerás a más personas interesadas en causar miedo. Éstas entrarán en tu vida porque tienen capacidad para rellenar de contenido una emoción que tu inconsciente desea expresar (Torrabadella, 1998, p. 28).

\subsubsection{La autoestima.}

La autoestima es la valoración de uno mismo. Autoestima implica tener sentimientos positivos hacia uno mismo y confianza en las propias capacidades para hacer frente a los retos que se plantean.

Torrabadella (1998) indica que la autoestima tiene dos vertientes:

- Gustarte: reconocerse y aceptarse es lo contrario de sentir vergüenza de uno mismo, está relacionado con sentirse bien con uno mismo y saberse digno de estima (nivel interno).

- Valorarte: creerte importante frente a los demás. Tener confianza en las propias posibilidades y la noción básica de que tienes las riendas de tu vida (nivel externo).

Comprender cómo eres implica conocer tus cualidades y tus puntos débiles. Para desarrollar una autoestima auténtica es necesario conocer tus cualidades y tus puntos débiles, de lo contrario se desarrollará una actitud defensiva y autojustificadora. La construcción de la autoestima está muy relacionada con el desarrollo social y afectivo en la infancia como reflejo de las identificaciones que se generan de las figuras significativas, encontradas fundamentalmente en el las relaciones familiares (Marín, Quintero y Rivera, 2019). 
Para conocerte realmente puedes valorar lo positivo y tus cualidades sabiendo que tienes que superar lo negativo. Algunas de las cosas que se puede hacer para favorecer la autoestima son las siguientes (Hue, 2007):

- Detectar los pensamientos automáticos críticos y limitadores de tu propia imagen. Una técnica útil para sustituir los pensamientos automáticos críticos y limitadores de ti mismo por otros más positivos, es la de imaginar que en tu interior existe una persona superior (fuerte, sensata, admirable, etc.) que te cree y admira y espera grandes cosas de ti además de apoyarte incondicionalmente. Una vez creado este líder interior puedes adoptar su forma de pensar de manera automática asociada a esta imagen, puedes evocar esta imagen para aprender de ella, pues representa tu ser más pleno, sensato y feliz.

- Procurar valorarte y cuidarte tanto físicamente (comer sano, hacer ejercicio, conservar un estado de saludable, etc.) como psicológicamente, intercambiando afecto con las personas que te rodean. Algunas estrategias que se pueden utilizar para valorarte son las siguientes:

- Date estima a ti mismo:

- Háblate con cariño: si analizas lo que piensas para ti, no siempre te tratas con amabilidad, recálcate tus cualidades y date ánimo.

- Cuando camines aprovecha para pensar que tu columna vertebral es el símbolo de tu fuerza interior y del orgullo de ser tú mismo. Siente tu cuerpo más allá del uso que le des en ese momento.

- Aprovecha cualquier ocasión para mover tu cuerpo, subir andando en vez de en ascensor, correr al atardecer por un sitio tranquilo, etc.

- Aliméntate de forma sana, escuchando lo que te pide tu propio cuerpo.

- Haz algo que te gusta hacer cada día sólo por el placer de hacerlo. Convierte ese momento en un ritual, respétalo y hazlo tranquilamente como un culto a ti mismo.

- Da afecto cuando lo tengas, demuestra dar amor a quienes te rodean.

- Haz un acto de amabilidad cada día. Ejemplo: sujetar la puerta, llevar las bolsas, etc. 
- Practica la empatía: ponte en el lugar de los demás entendiendo sus motivos y sentimientos.

- Mira a las personas a los ojos y sonríe.

- Pide a los demás su opinión.

- Pide afecto cuando lo necesites, dejando que los demás sepan que buscas cariño y comprensión:

- Expresa tus sentimientos, tanto como la ocasión lo permita.

- Rodéate de personas capaces de darte estima, que te respeten y te hagan sentir bien.

- Abandona las relaciones que te perjudican.

- Si alguien te interesa, muéstrale tu interés, háblale y pregúntale. Cualquier ocasión es buena para intercambiar una amable interacción.

- Acepta el afecto que otros te dan:

- Reconoce los elogios de los demás, esperando un breve periodo de tiempo para responder.

- Procura acostumbrarte a que te aprecien, exponiéndote a situaciones en que sabes que esto pasa.

- Dedícale tiempo a la ternura y afecto de los demás.

- Pide explícitamente lo que deseas, sin esperar a que los demás lo hagan.

- Agradece las estimaciones después de un tiempo. Ejemplo: la semana pasada me dijiste que alguien como yo era capaz de todo y me sentí imponente.

- Rechaza los estímulos afectivos que no quieras:

- Contradice las opiniones en las que no estés de acuerdo amablemente.

- Prescinde de las personas que perseveran en tratarte como tú no deseas y no tardes en hacerlo.

- No seas amable con la gente que detestas.

- Sé explícito. Expresa de forma clara las cuestiones que te molestan. 
- El rechazo más claro es el que se emite de forma no verbal: con el tono de voz y la expresión de la cara.

Recomendamos en este punto realizar el ejercicio 1.2: Ejercicios para fomentar la autoestima, ubicado en el anexo del documento.

\subsubsection{Regulación emocional.}

La tensión emocional continua puede desembocar en una situación muscular crónica, que nos puede impedir manifestar nuestras emociones, Bisquerra (2000) lo denomina "bloqueo emocional," éste crea una coraza y conlleva una incapacidad para manifestar o exteriorizar una emoción. Para este autor, el control emocional significa tomar conciencia de esos bloqueos y actuar de forma adecuada.

Variables a trabajar para el control emocional:

1. Fisiológicas: respuestas orgánicas. Procedimientos para controlar la activación: técnicas de relajación.

2. Cognitivas: pensamientos, percepción y evaluación subjetiva de los estímulos y estados asociados a las emociones. Planes y sistemas de autorregulación (planificación, autoverbalizaciones positivas, estrategias de afrontamiento, etc.).

3. Motoras o conductuales: comportamiento verbal y no verbal. Los componentes verbales y no verbales y su significado los trataremos con más detalle en la segunda parte de este documento (competencia social).

3. Variables fisiológicas:

Para el desarrollo de habilidades de control emocional, a nivel más somático o fisiológico se pueden realizar las siguientes estrategias:

- Inhibición motora. La primera actuación para lograr el control emocional, será el control del propio cuerpo, conocerlo y controlarlo. En nuestro cuerpo, existen conductas subcorticales y autónomas que tendremos que aprender a conocer y a describir para luego controlar, como la respiración acelerada, la 
sudoración, la falta de aire para respirar, etc. Sin embargo, estas conductas, se producen como respuesta en nuestro cuerpo, no en nuestra mente. Por ello, se puede aprender a controlar a través del cuerpo, del ejercicio físico, a través del control de la respiración, control muscular, etc.

Las técnicas por excelencia para lograr el control emocional son las técnicas de relajación (Payne, 2005). Una técnica muy conocida de relajación es la relajación progresiva de Jacobson.

Los ejercicios de respiración completa, son muy importantes para aprender a relajarnos y a aprovechar al máximo nuestra capacidad pulmonar para lograr un estado fisiológico de bienestar. Par lograrlo, lo importante es lograr una respiración correcta, que se basa en una respiración prolongada, inspirar sin forzar de forma lenta y prolongada, que haya un intervalo entre inspiración y expiración y espiración profunda (Ruibal y Serrano, 2001). La respiración completa se basa en las siguientes aportaciones:

- En condiciones normales, sólo utilizamos el 20\%-30\% de nuestra capacidad pulmonar.

- Las consecuencias de una escasa oxigenación pulmonar son:

- Menor oxigenación en los tejidos

- El sistema cardiovascular trabaja más

- Existe una mayor intoxicación general

- Existe un mayor riesgo de ansiedad y fatiga muscular

Para lograr la respiración completa es necesario utilizar los tres tipos de respiración, abdominal o diafragmática, torácica y clavicular (Ruibal y Serrano, 2001). A continuación, se describen los pasos a seguir para ello (ver ejercicio 1.3 de los anexos):

$1^{\circ}$ Llevar el aire a la parte más baja de los pulmones

$2^{\circ}$ Llevar el aire a la parte inferior y media de los pulmones

$3^{\circ}$ Realizar una inspiración completa 
$4^{\circ}$ Realizar la espiración más completa y regular

$5^{\circ}$ Alternancia respiratoria inspiración-espiración.

$6^{\circ}$ Generalizar la respuesta de respiración completa en condiciones naturales.

2. Variables cognitivas:

- Autocontrol. El autocontrol se encuentra en el estadio intermedio entre la inhibición motora y el control mental de la emoción. El autocontrol se refiere al control de las respuestas emocionales dirigiendo adecuadamente su expresión.

El objetivo de lograr autocontrol, es conocer cómo las relaciones de nuestro cuerpo afectan a nuestra mente y cómo los pensamientos negativos tienen una influencia negativa sobre nuestra conducta.

Generalmente, el descontrol emocional es fruto de la frustración y ésta es consecuencia de un desajuste entre las expectativas o deseos personales y las posibilidades reales o alcanzadas. Para lograr disminuir dicha frustración, en primer lugar, es necesario conocer cuáles son los hechos que nos desequilibran emocionalmente. En, segundo lugar se debe bien, o disminuir las expectativas, deseos o intereses o por otro lado, aumentar nuestras capacidades, habilidades o competencias para alcanzarlas.

Por otro lado, para lograr un mayor autocontrol, es necesario tener un mayor control mental. El control mental proviene de los pensamientos que generamos en nuestra mente y la forma que ejercemos control sobre ellos.

Muchas veces, se generan pensamientos negativos de forma automática, que no controlamos porque no somos conscientes de ellos. Normalmente se trata de pensamientos absolutistas, basados en creencias irracionales que nos generan malestar o depresión.

$\mathrm{Si}$ queremos lograr un mayor control mental, tendremos que detectar y controlar estas creencias irracionales para conocer en qué medida nos 
afectan en las decisiones que tomamos y en la vivencia de los acontecimientos, con el fin de modificarlas y cambiarlas por otros pensamientos más positivos.

Las características fundamentales de las creencias irracionales son que deforman de una manera negativa e invariablemente la realidad en contra de uno mismo. Güel y Muñoz (2000) definen estas creencias como distorsiones cognitivas en forma de hábitos de pensamiento que utilizamos para deformar negativamente la realidad.

Según Güel y Muñoz (2000) algunas de estas distorsiones cognitivas se basan en las siguientes características:

- Etiquetado: hacer una definición negativa y global de uno mismo.

- Hipergeneralización: establecer una regla general a partir de un hecho aislado.

- Filtrado: percibir solamente los estímulos negativos de las situaciones.

- Autoacusación: sentirte responsable de las cosas que no están a tu alcance.

- Pensamiento polarizado: radicalizar situaciones en las que todo debe ser perfecto si no ya no vale.

- Lectura del pensamiento: suponer que no gustas a los demás, que te critican sin evidencia alguna que pueda demostrar estas suposiciones.

- Magnificación y minimización: exagerar la importancia de las cosas malas y minimizar la de las buenas.

- Razonamiento emocional: suponer que las cosas son como tú las sientes y asociarlas a tus rasgos de personalidad como algo estable. Ej. Me siento como un inútil, por lo tanto debo ser un inútil.

- El deber: los mensajes establecidos como "debería" que no se han cumplido provocan sentimientos de culpabilidad. Si se dirige estos pensamientos hacia los demás se provoca resentimiento y frustración.

- Sistemas y planes de autorregulación: son mecanismos para regular nuestro propio comportamiento en función de los objetivos y expectativas que tengamos. Algunos de estos mecanismos son los siguientes: 
- Las autoinstrucciones. Se basan en los mensajes una persona se formula a sí misma de forma encubierta en relación a su propio comportamiento.

- La autoobservación. Es la observación de la propia conducta, dicha observación facilita la propia regulación de la conducta. La atención dirigida a uno mismo, conduce a la autoevaluación, si esta revela un estado de discrepancia entre la propia conducta y los patrones u objetivos deseados, el individuo experimenta incomodidad e intenta retirarse de la situación o por el contrario, intenta disminuir dicha discrepancia entre lo obtenido y lo deseado, cambiando su conducta.

Un grado de autoconciencia puede ser beneficioso hasta un punto en que se vuelve desadaptativo. Se ha demostrado que una excesiva autoconciencia puede ser generadora de ansiedad causada por una autocrítica excesiva o un fracaso a la hora de interpretar las acciones efectivas de las que no lo son.

- Las autoverbalizaciones. Son diálogos internos que las personas establecen consigo mismas o pensamientos automáticos que se generan de forma inconsciente. Las autoverbalizaciones negativas suelen estar presentes en las personas que poseen menor desarrollo de las habilidades interpersonales. Debemos modificar las autoverbalizaciones negativas por positivas consiguiendo un pensamiento positivo, dirigiendo el pensamiento hacia ideas positivas que generen e incrementen la confianza en nosotros mismos.

- Afrontamiento de las emociones: el afrontamiento de las emociones (coping) se basa en que la voluntad y el carácter son las habilidades para controlar el impulso emocional. Las técnicas de afrontamiento se han descrito como la realización de esfuerzos cognitivos y de comportamiento para manejar las demandas específicas de la situación que se aprecian como una carga o que exceden a los recursos personales (Lazarus, 1991). El afrontamiento suele ser más común en las emociones negativas que en las positivas.

Manejar las emociones puede requerir de una dedicación continua, hay dos formas de enfrentarse a las emociones: 
- Centrarse en el problema para resolver la situación.

- Centrarse en la emoción cambiando el significado personal de la situación. Se modifica el significado personal que genera la emoción. Significa un cambio de perspectiva en la visión del problema. 


\section{COMPETENCIA SOCIAL: DESARROLLO DE LAS HABILIDADES INTERPERSONALES.}

La competencia social, se ha definido como aquella que permite establecer relaciones adecuadas satisfactorias, con uno mismo y el entorno. De este modo, se pueden establecer una adecuada comunicación interpersonal gracias al desarrollo de las habilidades sociales.

Las habilidades sociales, se definen como un conjunto de conductas emitidas por el individuo en un contexto interpersonal, que expresa sus sentimientos, sus deseos, actitudes, opiniones, derechos de un modo adecuado a la situación respetando dichas conductas en los demás y que generalmente resuelven los problemas de la situación mientras minimizan la aparición de otros futuros problemas (Caballo, 1986).

\subsection{LA COMUNICACIÓN INTERPERSONAL Y SUS COMPONENTES}

La comunicación interpersonal es la que se lleva a cabo entre dos o más personas. Normalmente ocurre de modo espontáneo y se puede dar en un ambiente tanto formal como informal.

La comunicación es el elemento clave de la vida social, es el medio a través del cual las personas intercambian información, conocimientos, opiniones, emociones para relacionarse de forma eficaz.

El proceso de comunicación se ha definido como el conjunto de medios simbólicos por el que las personas transmiten mensajes (Borstein y Borstein, 1998).

Los objetivos de los programas de intervención en el ámbito de la comunicación se agrupan en cuatro áreas:

- Aspectos básicos de la comunicación

- Principios de la comunicación

- Conductas no verbales

- Conductas paraverbales. 
En este sentido, los componentes de la comunicación verbal, paraverbal y no verbal serían los siguientes:

- Componentes verbales (discurso verbal: hablado o escrito).

- Componentes paraverbales (Discurso del componente vocal del lenguaje sin su contenido: volumen de la voz, entonación, ritmo, pausas, etc.).

- Componentes no verbales (Anguera, 1996):

- Kinesia: expresiones, postura y gestos

- Proxemia: Espacio interpersonal

- Apariencia personal: autopresentación

Nos centraremos en los aspectos no verbales y paraverbales, así como en el estilo de comportamiento interpersonal con el fin de promover una comunicación efectiva en el ámbito educativo.

\subsection{LA COMUNICACIÓN NO VERBAL}

La comunicación no verbal existe siempre que se establece una interacción, es inherente a la hora de establecer una interacción con las demás personas.

La comunicación no verbal se podría tomar como acto comunicativo que se sirve de la expresión corporal, gestual y postural para compartir significados simbólicos. Se trata de la expresión de nuestra actitud personal en relación con el mensaje que transmitimos a través de nuestra expresión corporal, los gestos, el tono de voz, el volumen, la mirada, entre otros elementos paraverbales y no verbales.

Los mensajes no verbales tienen varias funciones, entre otras encontramos:

- Reemplazar a las palabras

- Repetir lo que se está diciendo (mover la mano para decir hola)

- Enfatizar un mensaje verbal y regular la interacción.

Por otro lado, el mensaje no verbal puede contradecir al mensaje verbal, esto no suele ocurrir de forma intencionada, pero la expresión facial o un movimiento de 
las manos pueden revelar verdaderos sentimientos negados por el contenido verbal del mensaje.

En este punto, es necesario destacar la importancia del cuerpo como elemento transmisor y receptor de conocimientos. Pont (2010) en su obra, La Comunicación no verbal, nos habla de los siguientes aspectos:

- La importancia del lenguaje del cuerpo. Transmitir información verbal y aportar información complementaria, suplementaria y sustitutiva (actitudes y sentimientos) El antropólogo Ray Birdwistell y el psicólogo clínico A. Mehrabian y otros, descubrieron que el componente verbal en una conversación cara a cara, el 93\% proviene de dos ámbitos: el tono y la intención que mostramos cuando hablamos en un 38\%, el movimiento y la proyección de nuestro cuerpo en un $55 \%$ y el $7 \%$ que es la comunicación oral, palabras y emisión de la voz.

- El yo del sujeto; al principio es un yo corporal que deriva de las sensaciones del cuerpo, principalmente de aquellas de su superficie, la piel. El Yo piel de Anzieu (2007) describe cómo las primeras formas de comunicación son a través de la comunicación táctil, paraverbal y no verbal. Por lo que se puede afirmar que hay modelos de comportamiento psicomotor que se constituyen precozmente en el bebé como consecuencias de todas las interacciones tempranas.

La comunicación no verbal con respecto al ámbito educativo, crea lazos empáticos y de asertividad. "El gran objetivo en la educación debe ser la comunicación efectiva y afectiva" (Vilaginés, 2007, p.32), se puede pensar en el acto comunicativo como una puesta en escena, y se puede plantear el acto comunicativo como producir dentro del seno de nuestro escenario comunicativo una composición dramática (acción) que ayude, facilite, incentive y motive al interlocutor (Amar, 2014).

La comunicación no verbal en la cultura educativa, se entiende del siguiente modo: 
- Cultura inspirada en la elegancia estilística. Cultura que se verbalice a través de los gestos y sea un lugar de compromiso estético.

- La cultura de aula debe estar impregnada de la singularidad de las relaciones humanas.

- Facilitar una comunicación bidireccional gracias al conocimiento de nuestro cuerpo y las posibilidades de su lenguaje: mejora la cohesión del grupo, la moral, su confianza y el grado de apertura.

- Facilitar un modelo de comunicación asertiva. Nuestros gestos y miradas proyectan emociones y disposiciones.

A continuación, describiremos los componentes no verbales y paraverbales para comprender mejor este tipo de comunicación no verbal, siguiendo la figura 3 , tomando las ideas de Anguera (1989), Castañer (2001) y Amar (2014).

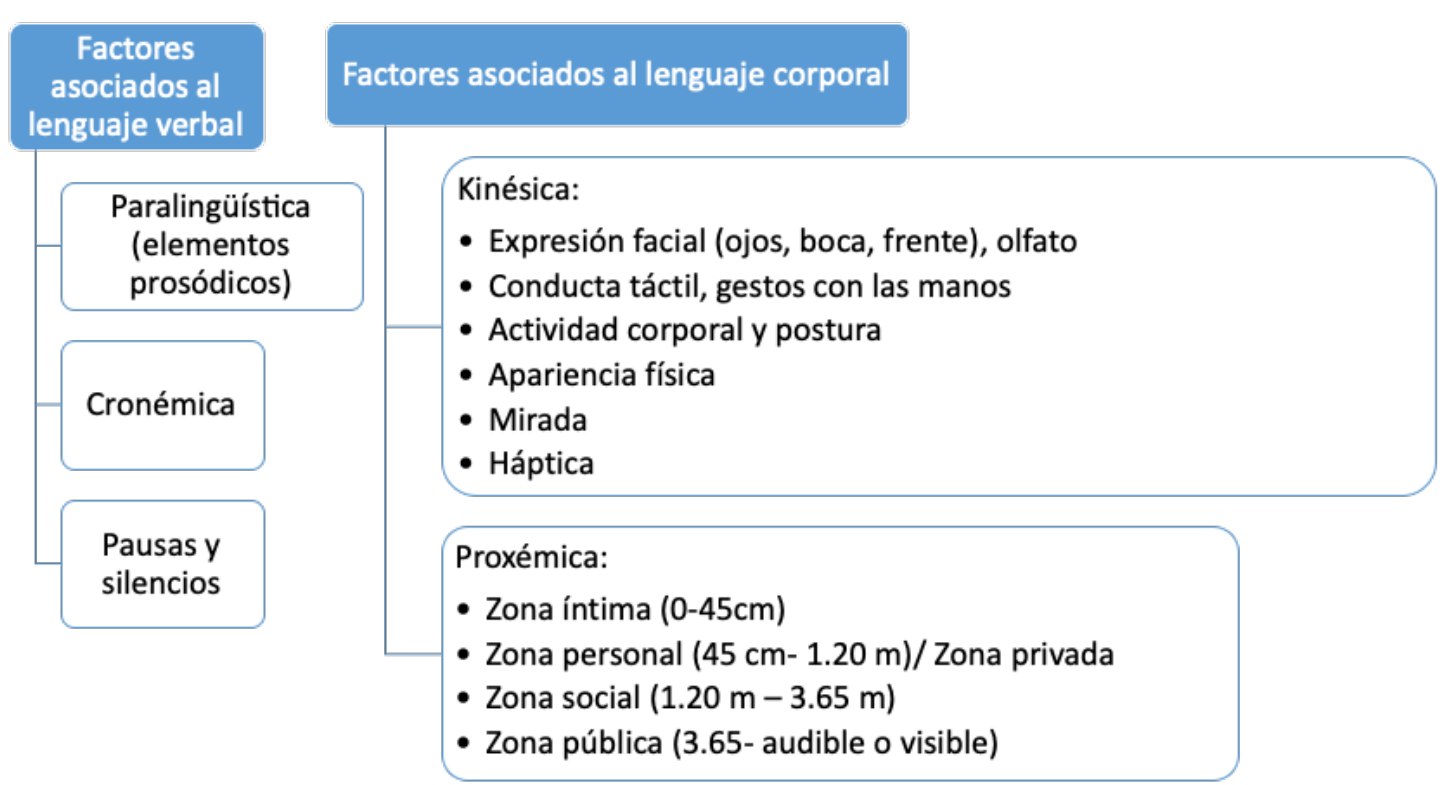

Figura 3. Estructura de los factores asociados al lenguaje verbal y corporal (elaboración propia, adaptado de Anguera, 1989; Casatañer, 2001; Amar, 2014).

\subsubsection{Componentes no verbales.}

Los componentes no verbales se agrupan en el estudio de la kinesia (gestos) y la proxémica (distancia interpersonal).

La kinesia se puede entender como el estudio de los gestos del rostro y de las distintas partes del cuerpo. Los gestos son acciones que acompañan al cuerpo 
definiéndose por el movimiento del rostro, de las manos o de otras partes del cuerpo con que se expresan diversos estados de ánimo, o acompañan al habla para ilustrar y ampliar el mensaje que se quiere proporcionar, o incluso pueden servir para sustituir al habla.

Los gestos pueden ser cualquier acción que envía un estímulo visual a un observador y para ser considerados como tales, tienen que comunicar alguna información.

Los gestos son básicamente culturales, por ser aceptados y utilizados normalmente en una cultura. También existen gestos universales.

Estudiaremos en relación a los gestos, la expresión facial, la mirada, la sonrisa y la postura y en relación a la proxémica, los distintos tipos de distancia interpersonal que pueden existir en la comunicación y finalmente la apariencia personal que es un aspecto sociocultural de la comunicación.

1. Expresión facial. La expresión facial juega varios papeles en la interacción social humana, entre otros (Anguera, 1989):

- Muestra el estado emocional del interlocutor, aunque este pueda tratar de ocultarlo.

- Proporciona una información continua sobre el interlocutor, sobre si comprende, si está sorprendido, está de acuerdo o no, respecto a lo que se está diciendo.

- Indica actitudes hacia los demás.

- Puede actuar más allá del propio lenguaje verbal, modificando o comentando lo que se está diciendo o haciendo al mismo tiempo.

\section{Mirada.}

Junto con la sonrisa, es la expresión facial fundamental. La mirada se define como el modo de mirar o la expresión de los ojos, que consiste en mirar a otra persona a los ojos o, más generalmente, en la mitad superior de la cara. La mirada mutua implica que se ha hecho contacto ocular con otra persona. 
La mirada es tanto una señal (a través del emisor), indicando que estamos atendiendo a los demás y un canal (a través del receptor) en la percepción de señales no verbales de los demás.

La mirada presenta las siguientes funciones (Angera, 1989):

- Sincronizar, acompañar o comentar la palabra hablada.

- Abrir y cerrar los canales de comunicación y regular los turnos de palabra.

- Un periodo de contacto ocular normalmente es un indicador para que comience una interacción.

- En una interacción normalmente el que escucha mira al que habla, y la mirada del que habla puede desviarse la mayor parte del tiempo mientras habla.

- A su vez, el que habla, se encontrará con la mirada del que escucha para averiguar o comprobar si está atento y para señalar su turno de palabra.

La media del tiempo en que las personas se pasan mirando durante una conversación es la siguiente:

- Mientras se escucha: $75 \%$

- Mientras se habla: $40 \%$

- Mirada mutua: $30 \%$

La mayor probabilidad de desviar la mirada de una fuente de información en general resulta cuando se ejecuta alguna tarea relacionada con el pensamiento (por ejemplo, al preparar una emisión verbal, cuando se vacila, o cuando se habla de forma entrecortada)

La máxima probabilidad de mirar al compañero se logra al final de la oración, en puntos estratégicos del habla, al hacer preguntas cortas, cuando envía señales de atención o cuando ríe. La cantidad y tipos de mirada indican ciertas actitudes interpersonales y formas de interacción que tienen distintos significados, por ejemplo (Caballo, 2015):

- Iniciar y mantener el contacto ocular con otra persona, es señal de implicación en el contacto interpersonal. 
- La gente que mira más es vista como más agradable. Mirar más intensifica la impresión de algunas emociones, como la ira, el agrado o el interés y el aumento notable del contacto ocular denota mayor intimidad. La mirada fija indica sentimientos activos de una manera amistosa, hostilidad o temerosa.

- Mirar menos intensifica otras emociones, como la vergüenza.

- En general, se mira más cuando:

- $\quad$ Se está físicamente lejos del compañero.

- Se habla de temas triviales, impersonales, no hay nada más que mirar.

- $\quad$ Se posee un estatus superior al compañero.

- Se pertenece a una cultura que enfatiza el contacto visual en la interacción.

- $\quad$ Se es extravertido.

- $\quad$ Se tienen grandes necesidades de afiliación o de inclusión.

- Desviar o evitar la mirada o la ausencia de mirada indica, por lo general, el deseo de evitar el contacto interpersonal.

- La ausencia de atención visual, normalmente indica desinterés o poca implicación en el discurso o el mensaje de la otra persona.

- Desviar la mirada va unido a la timidez, superioridad ocasional o sumisión cabizbaja (dejar de mirar el primero es signo de sumisión), también indica tristeza o apatía.

\section{Sonrisa:}

La sonrisa es una expresión facial utilizada para transmitir y emitir emociones diversas asociadas con el placer o entretenimiento, pero también cumple una función defensiva al utilizarse para ocultar emociones.

Una sonrisa puede suavizar un rechazo, comunicar una actitud amigable, y animar a los demás a que te devuelvan una sonrisa.

Tipos de sonrisa existentes: 
- Sonrisa auténtica: expresión de todas las experiencias emocionales positivas, con diferencias en la intensidad y mímica y en el tiempo de duración.

- Sonrisa amortiguada: la persona manifiesta sentimientos positivos disimulando su verdadera intensidad.

- Sonrisa triste: pone de manifiesto la experiencia de emociones negativas.

- Sonrisa de mitigadora: muestra la intención de limar asperezas de un mensaje desagradable o crítico, forzando al receptor de la crítica a la que devuelva la sonrisa, a pesar de la molestia que pueda producir.

- Sonrisa falsa: su intención es convencer al otro de que se siente una emoción positiva, cuando en realidad no es así. Parecerá inapropiada por el tiempo de duración.

\section{Postura corporal:}

Existen cuatro posturas básicas: de pie, sentado, agachado o arrodillado y tumbado (Caballo, 2015). Cada una puede ser subdividida por la manera que se lleva a cabo con los miembros del cuerpo entorno a una postura determinada.

Las posturas de las personas se adoptan en función de las convenciones culturales dominantes de una situación y de la actitud de una persona hacia los otros presentes.

Las posturas sirven para comunicar distintos rasgos de la conducta como las actitudes, las emociones y el acompañamiento del habla (Caballo, 2015):

1. Las actitudes. Se denominan posturas congruentes cuando las personas en una situación adoptan la misma postura simétrica o asimétrica, y se interpreta que las personas están adoptando el mismo punto de vista ante una situación determinada, expresando acuerdo ante la misma. Las posturas no congruentes, son aquellas que entre dos o más personas difieren en la forma de adoptarse ante una situación dada. Normalmente expresan desacuerdo o distanciamiento psicológico.

2. Las emociones. La postura puede comunicar diversas conductas afectivas como: 
- Indiferencia: hombros encogidos, brazos erguidos, manos extendidas

- Ira: inclinación hacia delante, brazos extendidos y puños apretados.

- Flirteo: varias clases de movimientos pélvicos, el cruzar y descruzar las piernas (en las mujeres).

3. Acompañamiento del habla. Los cambios importantes de postura se emplean para marcar amplias unidades del habla como en los cambios de tema, para dar énfasis y para señalar el tomar o ceder la palabra. Existen cuatro categorías posturales fundamentales (Caballo, 2015):

- Acercamiento: postura atenta caracterizada por una inclinación hacia delante del cuerpo. Se manifiesta con conductas que favorecen el contacto corporal (tocar, la aproximarse físicamente, mirar, buscar una orientación directa, apertura de brazos y piernas). Estas posturas de acercamiento comunican calidez, se utilizan para disminuir la distancia con el otro y aumentar la apertura, son amigables e íntimas etc. El acercamiento en situaciones inapropiadas o con desconocidos, puede resultar intimidatorio o amenazante.

- Retirada: es una postura negativa, de rechazo o repulsa. Se manifiesta retrocediendo, echándose hacia atrás o volviéndose hacia otro lado.

- Expansión: es una postura orgullosa, engreída, arrogante o de desprecio. Se manifiesta por la expansión del pecho, el tronco erecto o inclinado hacia atrás, cabeza erecta y hombros elevados.

- Contracción: es una postura depresiva, cabizbaja o abatida. Se manifiesta por un tronco inclinado hacia delante, cabeza hundida, hombros que cuelgan y un pecho hundido.

\section{Proxémica:}

Uno de los aspectos más estudiados dentro de la comunicación interpersonal es el de la proxémica, distancia interpersonal, la proximidad personal o el espacio interpersonal. La proxémica se ha definido como el uso de las zonas o espacios en relación a la distancia interpersonal, se habla también del uso de la territorialidad en el aula (Amar, 2914). El espacio interpersonal se define como 
el área mínima que una persona puede permitir alrededor del cuerpo a partir de la cual no pueden entrar las personas.

Dicho espacio personal varía de una cultura a otra. Normalmente en las culturas occidentales el espacio personal requerido es mayor que en otras culturas como las árabes, en la que se necesita menos espacio interpersonal.

Conforme aumenta la intimidad en una relación, hay una disminución gradual de la distancia interpersonal, de igual modo, la eliminación de las barreras de distancia puede facilitar una comunicación más íntima.

Existen cuatro tipos de distancia interpersonal diferentes a nivel psicológico en función de las situaciones sociales, dicha distancia se refiere a normas culturales implícitas (Caballo, 1989, 2015):

- Distancia íntima $(0-45 \mathrm{~cm}$.$) : Se da en las relaciones íntimas. En esta$ distancia, el contacto corporal es fácil, se puede oler, tocar al otro sin dificultad y se puede hablar en un tono bajo y en susurros.

- Personal (45- cm.- 1,20 cm.): Se da en las relaciones cercanas. En esta distancia, se puede tocar al otro y se le puede ver de forma completa, mejor que en la distancia íntima.

- Social $(1,20 \mathrm{~cm} \cdot-3,65 \mathrm{~cm}$.): Se da en las relaciones que ocurren de modo más impersonal. En esta distancia se necesita un mayor volumen de voz para ser escuchado.

- Pública (desde 3,65 m. hasta el límite de lo visible o audible): Se da en ocasiones públicas y en actos formales.

En el ámbito educativo, Amar (2014) incluye aspectos como el uso del entorno (luminosidad y acústica) y la densidad del aula (gran grupo, mediano grupo, pequeños grupos de trabajo, seminarios, acción tutorial). Además, indica dos cuestiones a tener en cuenta:

- El educador se moverá entre la zona pública y la privada. Estos espacios hay que conocerlos, tomar conciencia de la existencia de los mismos a fin de evitar la invasión del espacio del otro. 
- Se debe establecer una distancia confortable es fundamental. Algunas señales de incomodidad causadas por la invasión en el espacio de los estudiantes son el balanceo corporal, el movimiento de las piernas, los golpecitos y evasión de la mirada, etc. También puede ocurrir que haya una distancia excesiva para favorecer la comunicación, por lo que se procederá al acercamiento de los estudiantes para ello.

\section{Apariencia personal}

Se refiere al aspecto exterior de una persona. El aspecto físico está condicionado por los rasgos propios de una persona, las facciones y rasgos faciales, la complexión corporal, el peso, la altura, etc. y por los aspectos externos a ella como la ropa que lleva, los complementos o demás elementos que acompañan al aspecto físico.

Hoy en día, una persona puede cambiar de aspecto casi por completo. Desde el corte y color del pelo, maquillaje, aumento de la estatura por medio de tacones, e incluso el cambio del color de los ojos por medio de lentes de contacto.

Por otro lado, también es importante para causar una determinada impresión el uso de la ropa y los complementos que uno lleva con el fin de adecuarse a una situación determinada en función de la indumentaria que se lleve. Determinadas situaciones sociales, marcan normas protocolarias a la hora de adoptar una indumentaria $u$ otra, que deben ser tenidas en cuenta para acudir de modo apropiado a cada situación social que se presente. Por ejemplo, no iremos del mismo modo vestido para acudir a una fiesta, que a una reunión de trabajo.

El principal fin de la apariencia es la autopresentación, que indica el cómo se ve a sí mismo el que se presenta y cómo le gustaría ser tratado. La apariencia personal transmite impresiones sobre el atractivo, el estatus, el grado de conformidad, la inteligencia, la clase social, el estilo y gusto y edad de ese individuo.

A continuación, se resumen los componentes no verbales de la comunicación interpersonal. Cuadro adaptado de Caballo (2015) "Manual de evaluación y entrenamiento de habilidades sociales" (Tabla 6). 
Tabla 6. Aspectos no verbales de la comunicación interpersonal.

\begin{tabular}{|c|c|c|c|}
\hline $\begin{array}{c}\text { COMPONENTE } \\
\mathrm{S}\end{array}$ & $\begin{array}{l}\text { COMUNICACIÓN } \\
\text { EFECTIVA }\end{array}$ & FUNCIONES & OBSERVACIONES \\
\hline Mirada & $\begin{array}{ll}\text { Directa, horizontal y } \\
\text { relajada }\end{array}$ & $\begin{array}{l}\text { - Atención } \\
\text { - Percibir señales no } \\
\text { verbales del interlocutor }\end{array}$ & $\begin{array}{l}\text { Una mirada fija y directa } \\
\text { puede ser interpretada } \\
\text { como hostil, intimidante } \\
\text { y agresiva. }\end{array}$ \\
\hline Expresión facial & $\begin{array}{l}\text { Afirma o contradice el } \\
\text { mensaje verbal }\end{array}$ & 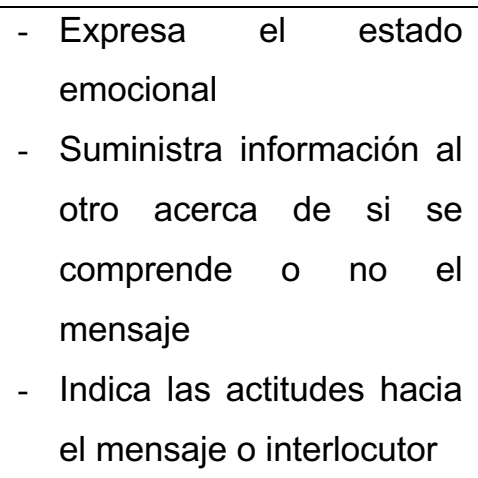 & $\begin{array}{l}\text { Evitar una expresión } \\
\text { incoherente, firme e } \\
\text { inexpresiva. }\end{array}$ \\
\hline Sonrisa & $\begin{array}{l}\text { Franca, abierta y } \\
\text { sincera } \\
\text { Coherente con la } \\
\text { situación interpersonal }\end{array}$ & $\begin{array}{l}\text { - Invita a la comunicación } \\
\text { - Actitud amigable }\end{array}$ & $\begin{array}{ll}\text { Evitar las sonrisas } \\
\text { falsas }\end{array}$ \\
\hline $\begin{array}{l}\text { Postura } \\
\text { orientación } \\
\text { corporal }\end{array}$ & $\begin{array}{l}\text { Erecta, relajada y } \\
\text { ligeramente inclinada } \\
\text { hacia delante }\end{array}$ & $\begin{array}{l}\text { - } \text { Refleja actitudes y } \\
\text { sentimientos }\end{array}$ & $\begin{array}{l}\text { Evitar posturas rígidas } \\
0 \quad \text { excesivamente } \\
\text { relajadas. }\end{array}$ \\
\hline $\begin{array}{l}\text { Gestos y } \\
\text { movimientos de } \\
\text { la cabeza }\end{array}$ & $\begin{array}{l}\text { - Coherente con el } \\
\text { estado de ánimo y } \\
\text { con el mensaje } \\
\text { - Sincronizados con lo } \\
\text { que se dice }\end{array}$ & $\begin{array}{l}\text { - Clarifican, refuerzan y } \\
\text { apoyan lo que se dice } \\
\text { - Indican las actitudes y el } \\
\text { estado de ánimo }\end{array}$ & $\begin{array}{l}\text { Evitar especialmente } \\
\text { los movimientos } \\
\text { estereotipados }\end{array}$ \\
\hline Distancia & $\begin{array}{l}\text { Mantener la distancia } \\
\text { correspondiente, } \\
\text { según el tipo de } \\
\text { situación }\end{array}$ & $\begin{array}{l}\text { - Indica la naturaleza de la } \\
\text { comunicación }\end{array}$ & $\begin{array}{lr}\text { Tranquilizar } & \text { al } \\
\text { interlocutor si se } \\
\text { traspasa alguna zona } \\
\text { interpersonal }\end{array}$ \\
\hline $\begin{array}{l}\text { Apariencia } \\
\text { personal }\end{array}$ & $\begin{array}{l}\text { Cuidada y adecuada a } \\
\text { la situación } \\
\text { interpersonal }\end{array}$ & $\begin{array}{l}\text { - Determina la impresión } \\
\text { que se provoca en el } \\
\text { interlocutor }\end{array}$ & $\begin{array}{lr}\text { Evitar una } & \text { apariencia } \\
\text { desaliñada } & \text { o } \\
\text { descuidada } & \end{array}$ \\
\hline
\end{tabular}


Finalmente indicar que la expresividad corporal se manifiesta de forma cotidiana a través de una gran cantidad de gestos involuntarios, naturales, expresando nuestros sentimientos más íntimos mediante gestos inconscientes. Cuando los observamos y tomamos conciencia de ellos, y del efecto que producen en los demás y empezamos a utilizarlos de forma debida para obtener las relaciones esperadas, los vamos precisando y acabamos por utilizarlos sin apercibirnos de ello (Mateu, 2006).

Además, podemos atender a otras cuestiones no citadas con anterioridad como el ritmo corporal (movimiento) entendido con los elementos de: vivacidad (vigorosidad de los movimientos), duración y momento (regularidad del ritmo corporal) y las coordenadas de distancia social y dirección (hacia dónde se dirige el cuerpo) (Amar, 2014).

\subsubsection{Elementos paralingüísticos en la comunicación no verbal.}

La paralingüística forma parte de la comunicación y de la oralidad que prioriza lo relacionado con las emisiones lingüísticas no verbales que están vinculadas con los elementos prosódicos del lenguaje, tales como el tono, el volumen o el ritmo de la voz (calidad de la voz, segregaciones o vocalizaciones). Incluye la acusmática, la escucha activa, la utilización de las pausas y los silencios y el uso de los tiempos para fomentar el diálogo entre otros elementos y se sirve de la escucha activa para fomentar la comunicación (Amar, 2014). En este sentido, es un tipo de escucha empática, definida como la capacidad de escuchar más allá de las palabras literales, comprender también los significados subyacentes y leer los sentimientos de quien habla, es decir, comprender no solo lo que se dice sino también lo que se siente, considerando el punto de vista de la otra persona y no solamente el propio.

Los componentes paraverbales más importantes son los siguientes:

1. Volumen de la voz

2. Entonación e inflexión

3. Timbre

4. Fluidez 


\section{Velocidad}

6. Claridad

7. Tiempo de habla

Las palabras que se utilizan en una interacción comunicativa dependen de la situación en la que uno se encuentra y del tema o contenido que se quiera tratar.

- Las interacciones comunicativas pueden ser situaciones formales (como por ejemplo una reunión de trabajo, una presentación pública, etc.) o informales (como por ejemplo una charla con los amigos, etc.).

- Los temas a tratar en una interacción comunicativa pueden ser variar de contenidos personales a temas impersonales, de temas abstractos a temas concretos, de temas internos del que habla como sentimientos, actitudes, pensamiento u opiniones, a temas externos, o de temas trascendentes $\mathrm{o}$ intrascendentes.

En ocasiones, podemos observar algunos defectos del que habla en la organización de su discurso oral:

- No organiza sus pensamientos antes de hablar

- Se expresa con imprecisión

- Intenta abarcar demasiado enunciado de modo que éste produce un efecto desconcertante. Seremos más eficaces si somos breves.

- Introduce demasiadas ideas en sus juicios con frecuencia sin relación entre sí de modo que el interlocutor encuentra difícil resumirlas.

- Sigue hablando por falta de seguridad.

A continuación, presentamos un cuadro resumen en el que se manifiestan algunas características de los elementos paralingüísticos en relación a las emociones y estados afectivos. Cuadro adaptado de Caballo (2015) "Manual de evaluación y entrenamiento de habilidades sociales" (Tabla 7) 
Tabla 7. Aspectos paralingüísticos de las emociones y estados afectivos.

\begin{tabular}{|c|c|c|c|c|}
\hline $\begin{array}{c}\text { ESTADO } \\
\text { AFECTIVO }\end{array}$ & VOLUMEN & TONO & VELOCIDAD & INFLEXIÓN \\
\hline Alegría & Alto & Agudo & Rápida & Hacia arriba \\
\hline Tristeza & Bajo & Grave & Lenta & Hacia abajo \\
\hline Impaciencia & Normal & $\begin{array}{c}\text { Normal a } \\
\text { moderadamente } \\
\text { agudo }\end{array}$ & $\begin{array}{c}\text { Moderadamente } \\
\text { rápida }\end{array}$ & $\begin{array}{l}\text { Ligeramente hacia } \\
\text { arriba }\end{array}$ \\
\hline Afecto & Bajo & Grave & Lenta & $\begin{array}{c}\text { Firme y } \\
\text { ligeramente hacia } \\
\text { arriba }\end{array}$ \\
\hline Aburrimiento & $\begin{array}{l}\text { Moderado a } \\
\text { bajo }\end{array}$ & Moderado a grave & $\begin{array}{c}\text { Moderadamente } \\
\text { lenta }\end{array}$ & $\begin{array}{c}\text { Monótona o } \\
\text { gradualmente } \\
\text { desfalleciente }\end{array}$ \\
\hline Satisfacción & Normal & Normal & Normal & $\begin{array}{l}\text { Ligeramente hacia } \\
\text { arriba }\end{array}$ \\
\hline Ira & Alto & Agudo & Rápida & $\begin{array}{l}\text { Irregular hacia } \\
\text { arriba y hacia } \\
\text { abajo }\end{array}$ \\
\hline
\end{tabular}

\subsection{DESAROLLO DE LAS HABILIDADES INTERPERSONALES.}

El desarrollo de las habilidades sociales e interpersonales implicaría conocer y desarrollar un estilo interpersonal asertivo. En relación a ello, se puede decir que existen tres estilos de comportamiento interpersonal, en función de cómo se relacionan las personas en la interacción social. Dichos estilos de comportamiento son los siguientes (Múñoz, Crespi y Angrehs, 2011; Rosales et al., 2013; Caballo, 2015):

- Estilo pasivo o conducta pasiva.

- Estilo agresivo o conducta agresiva.

- Estilo asertivo o conducta asertiva.

Podemos definir cada estilo del siguiente modo:

- Estilo pasivo: conductas de huida y de evitación. 
- Estilo agresivo: conductas de lucha y de enfrentamiento.

- Estilo asertivo: conductas de razonamiento y argumentación.

Normalmente, no existe un estilo de comportamiento interpersonal puro, dándose una mezcla de los tres estilos de comportamiento en una persona ante diferentes situaciones que pueden acontecer en la vida diaria. Para conocer el estilo de comportamiento asertivo y diferenciarlo de los demás, se va a proceder a definir los tres tipos de comportamiento para centrarnos finalmente, en el desarrollo de una conducta asertiva y su entrenamiento mediante técnicas asertivas.

\subsubsection{Estilo de comportamiento pasivo}

La persona que adopta un estilo de comportamiento pasivo en una interacción, no defiende sus propios derechos, esto implica que esta persona no es capaz de expresar sinceramente los propios sentimientos, pensamientos y opiniones, o bien que no sabe expresarlos porque no los reconoce abiertamente.

Las características del estilo de comportamiento pasivo, se expresa generalmente del siguiente modo:

- Permite que los demás se comporten de un modo agresivo.

- Aborda las decisiones tomadas de modo indirecto denotando una excesiva inseguridad.

- Emite comportamientos de evitación ante una situación en la que está implicado.

- Comportamiento no verbal centrado en conductas que emiten poca confianza y seguridad, tales como:

- Postura cerrada, encovada, hombros hacia abajo y cabeza baja.

- Movimientos forzados, rígidos o inquietos.

- Ausencia de contacto visual, mirada evitativa o cabizbaja.

- Voz baja y tono vacilante

- Movimiento general corporal tendente al alejamiento de los demás.

- Su comportamiento verbal se basa en: 
- Verbalizaciones caracterizadas por expresiones dubitativas del tipo: quizá, puede, supongo que, tal vez,... utilizando términos vagos y poco claros.

- Se disculpa con mucha frecuencia y emite mensajes indirectos sin expresar honestamente lo que desea, piensa y opina.

- Evita dar su opinión por miedo o vergüenza.

- Efectos sobre la personalidad y sobre su comportamiento:

- No alcanza sus objetivos y pierde oportunidades por su indecisión.

- Irritación, resentimiento consigo mismo y con los demás.

- Sentimientos de desagrado o compasión por parte de los demás.

- Conflictos interpersonales. Debido a sus problemas de comunicación y a la interpretación de su comportamiento por parte de los demás

- Baja autoestima y pobre autoconcepto. En general, tienden a tener una baja opinión de sí mismos y de su propio comportamiento. El estilo de comportamiento pasivo puede desarrollar patrones de conducta desadaptativos que, a largo plazo, pueden generar en trastornos de conducta o enfermedades mentales más graves como depresión o ansiedad generalizada, entre otras.

\subsubsection{Estilo de comportamiento agresivo.}

El estilo de comportamiento agresivo, se sitúa en el polo opuesto del comportamiento pasivo. El comportamiento agresivo, implica la defensa de los derechos personales y expresión de los pensamientos, sentimientos y opiniones sin respetar los derechos, pensamientos, sentimientos y opiniones de los demás.

Las personas que adoptan este tipo de comportamiento, plantean sus demandas de un modo impositivo y a menudo coercitivo, mostrando una postura exigente e intimidatoria hacia los demás, pudiendo llegar en casos extremos a la agresión física.

El comportamiento agresivo, a corto plazo puede tener respuestas favorables o desfavorables, aunque generalmente a largo plazo son desfavorables 
El estilo de comportamiento agresivo, se expresa generalmente del siguiente modo:

- Tendencia a mostrar superioridad ante una situación dada, expresando agresividad en las palabras, gestos y modos de actuar, exigencia, hostilidad e incluso ira.

- La intimidación es una forma general de negociación, también se basan en la burla y la humillación como un modo de dirigirse a los demás, considerándolos inferiores con respecto de sí mismos.

- Tendencia a aprovecharse normalmente de los demás, de su disponibilidad y quehacer.

- El comportamiento no verbal, se basa en:

- Postura corporal erecta y con hombros ligeramente inclinados hacia atrás.

- Movimientos, gestos y posturas amenazantes y bruscas.

- Mirada fija, intimidatoria y amenazante.

- Voz fría y tono de voz alto. Habla rápido y no permite interrupciones.

- Movimiento corporal con tendencia a invadir el espacio personal del interlocutor.

- El comportamiento verbal, se basa en:

- Verbalizaciones impositivas, acusadoras y ofensivas. Utilizando con frecuencia las palabras: "tienes que", "estarás bromeando", "siempre", "nunca",...

- Interrupciones a los demás, sin importarle las molestias o el desagrado que esto implica.

- Dar órdenes constantemente, decidiendo por los demás de un modo habitual.

- Insultos, exigencias, amenazas, reproches o etiquetas.

- Efectos sobre la personalidad y sobre su comportamiento:

- Puede alcanzar sus objetivos, aunque ocasionando perjuicios a los demás.

- Estados de tensión y enfado permanentes.

- Sentimientos de culpa, soledad y frustración constantes.

- Baja autoestima y pobre opinión de sí mismo. 
- Conflictos interpersonales de forma habitual, aunque los demás pueden reforzar estos comportamientos para evitar enfrentamientos.

- Aislamiento y disminución de las relaciones interpersonales ya que provoca en los demás sentimientos de enfadado, molestia e ira, lo que crea una tendencia a evitar a la persona que provoca este malestar.

- Baja autoestima, depresión o ansiedad. Debido al aislamiento se puede desarrollar un comportamiento desadaptativo generalizado que le ocasione trastornos de comportamiento más graves, al igual que ocurre con el estilo de comportamiento pasivo.

\subsubsection{Estilo de comportamiento asertivo.}

El estilo de comportamiento asertivo es el comportamiento ideal dentro de los tres estilos descritos. Representa el equilibrio frente al estilo de comportamiento pasivo y agresivo.

Poseer un estilo de comportamiento asertivo indica que la persona expresa sus sentimientos, pensamientos y opiniones y defiende sus derechos respetando los sentimientos, pensamientos, opiniones y derechos de los demás. La aserción significa respeto, no servilismo.

La persona que expresa y defiende sus propios derechos, y mantiene un comportamiento asertivo, logra alcanzar sus objetivos, de un modo honesto y respetuoso con los demás.

La conducta asertiva, se expresa generalmente del siguiente modo:

- Se orientan por "objetivos" no por miedo o por deseo de preponderancia, por lo que las probabilidades de alcanzarlos serán mayores que en otros estilos de comportamiento.

- Su comportamiento no verbal, se expresa del siguiente modo:

- Expresión del cuerpo abierta y relajada.

- Postura erguida.

- Movimientos faciales pausados y sin rigidez.

- Cabeza erguida. 
- Mantiene contacto visual de forma adecuada, mira a los ojos al hablar y al escuchar.

- Movimientos corporales orientados hacia el otro.

- Tono de voz firme y cálida.

- Espacio interpersonal adecuado.

- Su comportamiento verbal se basa en:

- La expresión de sus sentimientos, pensamientos y opiniones.

- Un lenguaje firme y directo y generalmente emplea mensajes en primera persona: “deseo", “opino”, “siento”, “comprendo”, etc.

- Utiliza con frecuencia verbalizaciones positivas en su discurso.

- Efectos sobre la personalidad y sobre su comportamiento:

- Logra alcanzar sus objetivos, establece sus objetivos y deseos con claridad.

- Defiende sus derechos y respeta los derechos de los demás.

- Satisfacción personal, autoconfianza y autoestima elevada.

- Elige por sí mismo y crea sus propias oportunidades.

- Permite a la otra persona ser escuchada y comprendida.

- Muestra empatía.

- Ofrece explicaciones cuando es posible.

- Facilita las relaciones interpersonales y sociales. Tiene un mayor número de relaciones interpersonales, y ayuda tanto para generarlas como para mantenerlas.

- Resuelve de un modo más adaptativo los conflictos interpersonales y los problemas que puedan surgir.

- Reduce el estrés y la ansiedad asociada a las situaciones conflictivas.

- Estilo de vida más adaptativo, con menor probabilidad de aparición de malestar y de trastornos de comportamiento.

Recomendamos realizar en este punto el ejercicio 2.1 de los anexos de competencia social: Identificación de conductas asertiva, agresiva y pasiva. 


\subsubsection{Los derechos asertivos, entrenamiento y técnicas asertivas.}

\subsubsection{Los derechos asertivos.}

Los derechos más frecuentemente implicados en estas clases de situación son:

- Derecho a ser tratado con respeto.

- Derecho a hacer peticiones o favores.

- Derecho a decir que no.

- Derecho a cambiar de opinión.

- Derecho a dar y recibir elogios.

- Derecho a pedir un cambio de comportamiento a otra persona.

- Derecho a defenderse de las críticas.

- Derecho a pedir un cambio en el otro.

- Derecho a no saber algo.

- Derecho a tener intimidad.

- Derecho a equivocarte.

- Derecho a tomar nuestras propias decisiones.

- Derecho a sentir emociones y expresarlas sin herir los sentimientos de los demás.

Se recomienda realizar en este punto el ejercicio 2.2 de competencia social de los anexos: los derechos asertivos.

\subsubsection{Pasos para el entrenamiento asertivo.}

1. Expresar cuidadosamente cuáles son sus derechos, qué es lo que se desea, lo que necesita y cuáles son sus ideas respecto a la situación.

2. Señalar el momento y un lugar para discutir el problema que le concierne entre las personas implicadas.

3. Caracterizar la situación problema de la forma más detallada posible.

4. Adaptar la definición de los sentimientos a los llamados "mensajes en primera persona"

5. Limitar mediante una o dos frases claras cuál es su objetivo de forma concreta y firme. 
6. Acentuar la posibilidad de obtener lo que se desea, si cuenta con la cooperación de la otra persona para que se den las circunstancias necesarias para ello. Si es necesario, expresar las consecuencias negativas que traerá su falta de cooperación.

\subsubsection{Técnicas asertivas.}

Las técnicas asertivas tienen la finalidad de facilitar una conducta asertiva modificando la conducta pasiva y agresiva. Algunas técnicas asertivas son las siguientes (Rosales et al., 2013; Caballo, 2015):

- Libre información: permite que nuestro interlocutor pueda hablar de si mismo con total libertad aprendiendo a escuchar atentamente a los demás y captar la información que nos dan. Esta técnica nos permite iniciar y continuar una conversación además de proponer algún tema interesante para el interlocutor; hacer preguntas, interesarse por lo que nos dice el otro, atender a nivel verbal y no verbal al interlocutor, etc. puede constituir una buena forma de comenzar una relación asertiva.

- Autorrevelación: consiste en proporcionar información sobre nosotros mismos sin que nos la pidan, a poder manifestar a nuestro interlocutor sobre lo que pensamos ante un tema que es objeto de conversación. Esta técnica facilita las relaciones interpersonales y demuestra que el escuchar y ser escuchado se complementan.

- Aprender a establecer pactos: se utiliza para poner puntos en común y llegar a acuerdos con los demás cuando hay una dificultad o discusión en términos completamente opuestos. Para establecer un pacto, éste debe cumplir con las siguientes condiciones: no debe ir contra la propia autoestima, no debe perjudicar a ninguna de las partes, no debe afectar de una manera emocional a las personas. El compromiso que se establezca, siembre comportará algún tipo de "concesiones" y de lo que se trata es que éstas no sean humillantes para ninguno ni vayan en contra de nuestros derechos asertivos.

- Aprender a decir que no: consiste en repetir de manera tranquila, serena y consistente nuestros deseos y emociones. La constancia será la virtud esencial de esta técnica. Se aplica cuando conviene decir que no ante 
determinadas situaciones. Para ello hay que hacerlo con seguridad, sin dar excusas y sin gritar ni utilizar un estilo de comportamiento agresivo. Es una de las técnicas más difíciles porque implica un alto grado de autoafirmación, evitará que nos manipulen y que nos sintamos culpables por haber dicho que sí cuando teníamos muy claro que queríamos decir que no.

Para aplicar esta técnica, se deben seguir los siguientes consejos:

- Responder sin agresividad, sin gritar y con un tono de voz tranquila.

- Mirar a los ojos del interlocutor y mantener una postura corporal relajada.

- Decidir cuál es el mensaje que se quiere dar y no cambiarlo.

- Ser constante con la negativa, si se dan razones, dar repetidamente las mismas razones y argumentos de tu postura (mensaje emitido).

- No dar explicaciones.

- Aprender a recibir críticas: las críticas sistemáticas pueden dañar negativamente a la autoestima y la seguridad personal, por eso es muy importante aprender a afrontarlas de forma asertiva. Las críticas provocan en muchas ocasiones, reacciones agresivas o de venganza, por ejemplo, atacando con otra crítica (comportamiento agresivo) o con reacciones pasivas de sumisión como callar, huir y llorar en silencio. Las técnicas que se proponen, son progresivas. Se aplican de menor a mayor dificultad. En la práctica, cuando una funciona se puede pasar a entrenar la siguiente.

Normas a seguir para recibir críticas:

- Evaluar si la crítica es cierta o no la crítica.

- No aceptar ninguna crítica que no sea cierta.

- Evaluar si las críticas están hechas de forma adecuada o no. Según se realice una crítica, si no es de forma adecuada (estilo agresivo), pedir un cambio en la forma de decirla. Aceptar la crítica, pero no la forma de hacerla.

- Aceptar las críticas que consideres ciertas o aceptar la posibilidad de que lo sean. 
- Pedir información concreta y precisa sobre las críticas atendiendo a conductas y situaciones. Descripción de la crítica lo más concreta posible: conducta, lugar y momento.

- Proponer un cambio en el comportamiento para mejorar la situación.

Técnicas útiles para aprender a recibir críticas:

- Banco de niebla. Técnica que nos enseña a aceptar las críticas sin negarlas, pudiendo aceptar la posibilidad de que nuestro crítico tenga razón. Consiste en responder a una crítica manipuladora con la expresión: "puede que si..." "puede que tengas razón", "no digo que no"..., pero sin llegar a dar la razón. Esta técnica exige que no se contraataque con otra crítica.

- Autoafirmación negativa. Consiste en reconocer claramente las críticas que nos han hecho sin excusarnos. La capacidad de reconocer los errores nos tranquiliza y nos evita actitudes defensivas y falsas ante las críticas. Es una técnica que se combina con la anterior, la base de esta técnica se basa en el derecho a equivocarse. La técnica sería aceptar la crítica si estamos de acuerdo con ella y es cierta. Tal como nos sugiere el ejemplo: "llegaste tarde el otro día" la autoafirmación negativa consiste en decir "sí, es verdad llegué tarde el otro día"

- Interrogación negativa. Consiste en pedir información adicional y provocar críticas sobre nuestra conducta. Esta técnica nos ayuda a ser asertivos, nos permite distinguir qué críticas son manipuladoras y conocer mejor nuestra manera de actuar. Esta técnica posibilita también mejorar la comunicación con el otro para conocer los diferentes puntos de vista. Es importante solicitar las críticas con seriedad, sin sarcasmo o agresividad y evitando criticar al otro. También se debe solicitar al otro que sea exacto en sus críticas, atendiendo a comportamientos que no considera adecuados y sin generalizar. Ejemplo: cuando alguien dice "todo lo haces mal" (crítica destructiva y manipuladora) conviene precisar "¿Podrías concretarme qué cosas hago mal y en qué momentos?". 


\section{- Aprender a realizar peticiones:}

Tomaremos las ideas de Caballo (2015) para explicar este apartado. Hacer peticiones podría implicar: pedir favores, pedir ayuda o pedir que otra persona cambie su conducta con respecto a un hecho o actitud. Realizar peticiones, no es sinónimo de exigencia, ya que, en este caso, se estaría violando los derechos de la otra persona. Al hacer peticiones, se tiene que reconocer el derecho de la otra persona a rechazar la petición. El reconocer los derechos de los demás es la mejor protección de los propios derechos. Tampoco se trata de hacer peticiones de manera indiscriminada, porque se puede llegar a ser una persona muy molesta para el otro, si estamos pidiendo continuamente favores innecesarios. Sin embargo, es muy razonable hacer peticiones cuando se necesita.

Algunas recomendaciones para practicar las habilidades de hacer peticiones son: ser directo, expresar la conducta que ha sido inapropiada y tus sentimientos con respecto a ella, y pedir un cambio en relación a ello. No es necesario ninguna justificación, aunque las explicaciones normalmente ayudan, no es necesaria ninguna disculpa, no hay que tomar una respuesta negativa de un modo personal, y prepararse tanto para un no como para un sí y respetar el derecho de la otra persona. Entender la diferencia entre razones y excusas. Una razón es un hecho que, si cambiase, cambiaría la respuesta, sin embargo, una excusa, es un hecho a pesar de que cambiara, no implicaría un cambio en la respuesta. Por ejemplo, el hecho de estar ocupado para no poder ir a un sitio, cambiaría la respuesta ante una petición si no se estuviese ocupado, de lo contrario, sería una excusa.

Se anima a realizar en este punto a realizar el ejercicio 2.3 de competencia social de los anexos: técnicas asertivas. 


\section{CONSIDERACIONES FINALES}

Para finalizar, se plantea que sería interesante contemplar todos los aspectos trabajados en este documento en el ámbito educativo, en todas sus etapas y comenzar con su construcción y trabajo, de un modo experiencial y vivencial desde la primera infancia, con el fin de que el alumnado pueda gestionar sus emociones y relacionarse de forma adecuada en el ámbito interpersonal. Un modelo en el cual se le permita y facilite al alumnado desarrollar competencias básicas personales y sociales ligadas a la colaboración, el cuidado, la autonomía y la responsabilidad personal y en donde el profesorado sea responsable y mediador de dichas competencias (Pacheco, Carpio y García, 2014). 


\section{REFERENCIAS}

Alban, A. (2007). Oratoria. El arte de hablar en público. Recuperado de www.eumed.net/libros/2007b/

Amar, V.M. (2014). Dídáctica y comunicación no verbal. Salamanca: Comunicación social.

Anguera, M.T. (1989). Metodología de la observación en las Ciencias Humanas. Madrid. Cátedra.

Anzieu, D. (2007). El yo-piel. Mad

Borstein y Borstein (1988). Entrenamiento en habilidades de comunicación. Terapia de pareja. Enfoque conductual sistémico. Madrid. Pirámide, 117-136.

Castañer, M. (2001). El cuerpo: gesto y mensaje no-verbal [Versión electrónica]. Revista Tándem, 3.

Damásio, A. (2005). En busca de Spinoza: neurobiología de la emoción y los sentimientos. Madrid: Crítica.

Davis, F. (1998). La comunicación no verbal. Madrid: Alianza Editorial.

Caballo, V.E. (1986). Evaluación de las habilidades sociales. En. R. FernándezBallesteros y J.A. Carrobles (Ed.). Evaluación conductual: metodológica y aplicaciones. Madrid: Pirámide.

Caballo, V.E. (1989). Teoría, evaluación y entrenamiento de las habilidades sociales. Valencia: Promolibro.

Caballo, V. E. (2015). Manual de evaluación y entrenamiento de las habilidades sociales. Siglo XXI: Madrid.

Bisquerra, R. (2000). Educación emocional y bienestar. Madrid: Praxis. 
Bisquerra, R. (2002). Orientación psicopedagógica y educación emocional en la educación formal y no formal, Agora Digital, 2, 1-13. Recuperado en marzo de 2015 de http://www.uhu.es/agora/version01/digital/numeros/02/02.

Bisquerra, R. (2009). Psicopedagogía de las emociones. Madrid: Síntesis.

Bisquerra, R. y García, E. (2018). La educación emocional requiere de formación de profesorado, Participación Educativa, 5(8), 13-28.

Gardner, H. (1995). Inteligencias múltiples. La teoría en la práctica. Barcelona: Paidós.

Gil, F. y León, J. M. (1998). Habilidades sociales. Síntesis. Madrid.

Goleman, D. (1996). Inteligencia emocional. Kairós: Barcelona.

Güel, M. y Muñoz, J. (2000). Desconócete a ti mismo. Programa de alfabetización emocional. Paidós: Barcelona.

Hidalgo, C. G. y Abarca N. M. (1999). Comunicación interpersonal. Alfaomega: Colombia.

Hue, C. (2007) Pensamiento emocional. Un método para el desarrollo de la autoestima y el liderazgo. Zaragoza: Mira.

Confederación de Empresarios de Aragón (CREA) (2007). Proyecto TREIN. Guía para el desarrollo de la Inteligencia Emocional en la Formación Continua. CREA: Zaragoza.

Larraz, N. (2015). Desarrollo de las habilidades creativas y metacognitivas en la educación secundaria obligatoria. Madrid: Dykinson

Lazarus, R.S. (1991). Emotion and adaptation. New York: Osford University Press.

López Sánchez, F. (2009). Las emociones en la educación. Madrid: Morata. 
Mayer, J.D. y Salovey, P. (1997). What is the emotional intelligence? En J.D. Mayer, \& P. Salovey (Eds.) Emotional development and emotional intelligence. New York: Basic Book.

Marín, M.P., Quintero, P.A., Rivera, S.C. (2019). Influencia de las relaciones familiares en la primera infancia. Poiésis, 36, 164-183. doi: https://doi.org/10.21501/16920945.3196.

Muñoz, C., Crespi, P. y Angrehs, R. (2011). Habilidades sociales. Madrid: Paraninfo.

Salovey, P. \& Mayer, J.D. (1990). Emotional intelligence. Imagination, cognition and personality, 9, pp. 185-211.

Pachecho, D.I., Carpio, D. y García, J.N. (2014). Estilos de relación interpersonal en la convivencia escolar. En J. N. García (Ed.). Prevención en dificultades del desarrollo y del aprendizaje (pp. 261-272). Pirámide.

Payne, R.A. (2005). Técnicas de relajación. Guía práctica. Paidotribo: Badalona.

Pelechano, V. (Dir.) (1996). Habilidades interpersonales. Teoría mínima y programas de intervención. Valencia: Promolilbro.

Pont, T. (2010). La comunicación no verbal. Barcelona: UOC

Punset, E., Bisquerra, R. y Gea, P. (2016). Universo de emociones. Valencia: Palaugea.

Ruibal, O. y Serrano, A. (2001). Respira unos minutos. Ejercicios sencillos de relajación. Inde: Barcelona.

Rosales, J.J., Caparrós, B.M., Molina, I. y Alonso, S.H. (2013). Habilidades sociales. McGraw-Hill.

Sternberg, R.J (1990). Más allá del cociente intelectual. Una teoría triárquica de la inteligencia humana. Bilbao: Desclée de Brower. 
Sternberg, R.J. (1997) (Ed.). Handbook of creativity. New York: Cambridge University Press.

Tizio, H. (2008). Reinvertar el vínculo educativo. Barcelona: Gedisa.

Torrabadella, P. (1998). Cómo desarrollar la inteligencia emocional. Test y ejercicios para aumentar la autoestima y actuar de manera positiva. Barcelona: RBA. 


\section{ANEXOS.}

\section{EJERCICIOS PRÁCTICOS SOBRE INTELIGENCIA EMOCIONALY COMUNICACIÓN INTERPERSONAL}

\section{COMPETENCIA PERSONAL: EMOCIONES Y CONTROL EMOCIONAL}

\subsection{Ejercicios de autoconocimiento emocional.}

Identifica situaciones donde hayas sentido diferentes emociones. Detalla al menos una situación donde hayas sentido la emoción que se detalla y los motivos que creas que te han llevado a ellas, tanto racionales como irracionales.

\begin{tabular}{|l|l|l|l|}
\hline & $\begin{array}{l}\text { SITUACIÓN } \\
\text { Personas } \\
\text { Lugares y objetos } \\
\text { presentes }\end{array}$ & MOTIVOS RACIONALES & $\begin{array}{l}\text { MOTIVOS } \\
\text { IRRACIONALES }\end{array}$ \\
\hline IRA & & & \\
\hline MIEDO & & & \\
\hline TRISTEZA & & & \\
& & & \\
\hline ANSIEDAD & & & \\
& & & \\
\hline
\end{tabular}




\begin{tabular}{|l|l|l|l|}
\hline ALEGRÍA & & & \\
& & & \\
\hline VERGÜENZA & & & \\
& & & \\
\hline
\end{tabular}

\subsection{Ejercicios para fomentar la autoestima.}

- 1. Ejercicio del árbol.

- Haz una lista de tus cualidades y los logros que éstas te permiten alcanzar.

- Dibuja un árbol donde las raíces del mismo sean tus cualidades y el fruto de las mismos sean tus logros.

- 2. Apunta tus debilidades e indica cómo te gustaría que se convirtiera en algo positivo y qué puedes hacer para cambiar.

- 3. En un cuadro haz un registro de las situaciones donde te envías mensajes críticos hacia tu persona. Coloca el lugar, la hora y la frase exacta del pensamiento.

\subsection{Ejercicio de relajación.}

Ejercicio de respiración completa. Pasos a seguir:

1. Posición:

- Tumbado en el suelo boca arriba, sobre una superficie blanda (manta, alfombra, esterilla, colchón u otra).

- Flexionar ligeramente las rodillas y separar los pies ligeramente (unos 20 $\mathrm{cm}$.). columna vertebral recta.

- Lugar de temperatura agradable, sin ruidos y luz moderada. 
- Buscar tensiones en el cuerpo, zonas o partes donde haya molestia o tensión y masajéalas mentalmente.

2. Concéntrate ahora en tu respiración. Entrenamiento:

1. Parte inferior de los pulmones:

- Colocar la mano izquierda sobre el vientre y la mano derecha sobre el pecho.

- Inspirar lentamente por la nariz y llena el vientre de aire, observa sin mirar cómo la mano izquierda se eleva poco a poco. La mano colocada en el pecho sin embargo apenas se mueve.

- Espirar el aire por la boca suave y lentamente, mientras la mano izquierda desciende.

- Realizar esta respiración tres veces.

2. Parte media de los pulmones:

- Colocar la mano izquierda sobre el vientre y la mano derecha sobre el la tripa.

- Inspirar lentamente por la nariz y llena el vientre de aire, observa sin mirar cómo la mano izquierda se eleva poco a poco.

- La mano colocada en la tripa se eleva en un segundo paso.

- Espirar el aire por la boca suave y lentamente, mientras las manos descienden, la derecha en primer lugar y la izquierda en segundo lugar, desciende.

- Realizar esta respiración tres veces.

3. Parte alta de los pulmones: Inspiración completa.

- Colocar la mano izquierda sobre el vientre y la mano derecha sobre el pecho.

- Inspirar lentamente por la nariz y llena el vientre de aire, observa sin mirar cómo la mano izquierda se eleva poco a poco.

- La tripa se eleva en un segundo paso y la mano colocada en el pecho se eleva en un tercer paso. 
- Espirar el aire por la boca suave y lentamente, mientras las manos descienden, la derecha en primer lugar y la izquierda en segundo lugar, desciende.

- Realizar esta respiración tres veces.

- Alargar sucesivamente la espiración.

\section{COMPETENCIA SOCIAL: DESARROLLO DE LAS HABILIDADES} SOCIALES (ejercicios adaptados de Güell y Muñoz, 2000).

\subsection{Identificación de conductas asertiva, agresiva y pasiva.}

De las siguientes situaciones debes identificar qué estilo de comportamiento adoptan los personajes A, B y C: asertivo, pasivo o agresivo.

1. Un compañero de clase y amigo te pide los apuntes de una asignatura. Tú los necesitas porque al día siguiente tienes un examen.
A. Les dices que no se los dejas.
B. Se los dejas, pero piensas que hubiera sido mejor no hacerlo.
C. Le dices que ya se busque la vida y que si se ha creído que tú te dedicas a ir por la vida haciendo caridad.

2. Haces cola en una tienda y un cliente que entra después pasa delante de ti. Tú no tienes prisa.
A. Le dices que es un maleducado y que no tiene vergüenza.
B. Como no tienes prisa, no le dices nada.
C. Le dices que tú estabas antes que él.

3. En una conversación en un bar con tus amigos, todos se ponen a hablar mal de M. Jackson, tanto de su vida privada como de su música. Sin embargo, a ti te gusta mucho M. Jackson.
A. Callas para no buscar problemas.
B. Participas en la conversación defendiendo a M. Jackson.
C. Dices a tus amigos que no tienen ni la menor idea de música y que más vale que vayan aprendiendo.

4. Tu hermana/o te estropea sin querer un $C D$ de música que tiene mucha importancia para ti.
A. Le gritas y te enfadas echándole una bronca enorme. 
B. Le explicas que era un recuerdo personal muy valorado por ti y que te ha molestado lo que ha pasado.

C. Te resignas y piensas que ya comprarás otro.

5. Un Fin de Semana, tu pareja te propone ir a la playa e insiste mucho en ello, pero tú tienes muchas ganas de ir a la montaña.
A. Le explicas los motivos de querer ir a la montaña y propones un pacto para ir un Fin de Semana a cada sitio.
B. Como es tu pareja y la quieres mucho, vas a la playa y cuando estás ahí piensas que hubieras estado mejor en la montaña.
C. Reprochas a tu pareja haber ido a la montaña, que siempre se ha de hacer lo que ella quiera y que no tiene en cuenta tus deseos.

6. Un profesor te suspende una prueba con un margen muy pequeño. El profesor tiene fama de tener muy mal genio. Tú crees que la prueba no está bien puntuada.
A. No vas a reclamar porque piensas que será peor.
B. Solicitas una entrevista con tu profesor y le expones tu punto de vista.
C. Difundes por todas partes que el profesor te tiene manía y que te ha sido injusto corrigiendo y que no es honesto.

\subsection{Los derechos asertivos.}

Realizar un role-playing (ensayo de roles) por grupos de trabajo:

1. Escoged una situación que sea susceptible de ser resuelta mediante las habilidades sociales ha de tenerse en cuenta algún derecho asertivo:

- Derecho a ser tratado con respeto.

- Derecho a hacer peticiones o favores.

- Derecho a decir que no.

- Derecho a cambiar de opinión.

- Derecho a dar y recibir elogios.

- Derecho a pedir un cambio de comportamiento a otra persona.

- Derecho a defenderse de las críticas.

- Derecho a pedir un cambio en el otro.

- Derecho a no saber algo. 
- Derecho a tener intimidad.

- Derecho a equivocarte.

- Derecho a tomar nuestras propias decisiones.

- Derecho a sentir emociones y expresarlas sin herir los sentimientos de los demás.

2. Resolver la situación mediante los tres tipos de comportamiento: asertivo, pasivo y agresivo, atendiendo a:

- Comportamiento no verbal: mirada, gestos, expresiones faciales y postura corporal.

- Comportamiento verbal: argumentos, ideas, tono de voz, velocidad del habla.

- Resolución final de la situación: si las partes implicadas en la situación están satisfechas con la solución tomada.

3. Escenificarlo para poder identificar los tres tipos de comportamiento ante el resto de compañeros.

\subsection{Técnicas asertivas.}

Por grupos de trabajo practicar mediante un role-playing las técnicas asertivas ante las siguientes situaciones:

- Situación 1: te encuentras en una fiesta en la que sólo conoces a un amigo que te ha llevado. Ves a una persona que te parece interesante y te acercas e inicias una conversación, sin ánimo de ligar, solamente por conocerla (técnica de autorrevelación)

- Situación 2: Hace tres meses que comenzó el curso y no has hablado casi nunca con uno de tus compañeros más que de cuestiones académicas. En una de las clases se sienta a tu lado ¿Cómo iniciarías una conversación? (técnica de libre información)

- Situación 3: Sois tres amigos que estáis organizando unas vacaciones juntos. Queréis viajar, pero no os ponéis de acuerdo ni sobre el lugar, ni sobre el destino, ni sobre la duración del viaje (técnica para establecer pactos). 
- Situación 4: Un amigo te llama repentinamente y te comenta que esa misma noche hay una fiesta muy especial en un local nuevo de la ciudad. Tu amigo te anima e insiste con muchos argumentos para que vayas, sin embargo, tú tienes otros planes ya que tienes que estudiar para un examen de idiomas que tienes en tres días y debes quedarte en casa (Técnica aprender a decir que no o del "disco rayado").

- Situación 5: Haces tu parte correspondiente de un trabajo y tus compañeros critican la forma en que lo has hecho. Tienes que responder ante tres críticas que puedan hacerte tus compañeros atendiendo a según el tipo y cómo estén realizadas, pueden estar centradas en aspectos personales, aspectos de relación o aspectos académicos. 